ISSN: 0213-2060

DOI: http://dx.doi.org/10.14201/shhme201432131158

\title{
LA EXPLOTACIÓN DIRECTA DE LA PROPIEDAD DOMINICAL MONÁSTICA EN LA CUENCA DEL DUERO. LOS CLUNIACENSES
}

\section{Direct Exploitation of the Dominical Monastic Property in the Duero River Basin. The Cluniacs}

Julio A. PÉREZ CELADA

Depto. de Ciencias Históricas y Geografía. Facultad de Humanidades y Educación. Universidad de Burgos. C/Villadiego,s/n.E-09001 BURGOS. C. e.: jperez@ubu.es

Recibido: 2014-04-02

Revisado: 2014-07-07

Aceptado: 2014-10-03

BIBLID [0213-2060(2014)32;131-158]

RESUMEN: La explotación directa constituyó una de las formas de aprovechamiento de las propiedades territoriales seńoriales en la Europa medieval. A lo largo de los siglos centrales de este periodo, dicha explotación directa fue experimentando una reducción que se aceleró en el siglo XIV, aunque con frecuencia no desapareció totalmente. Este proceso es constatable también en la cuenca del Duero, un espacio del que mostramos el ejemplo de un seńorío benedictino cluniacense que se caracteriza por su buena dotación informativa al respecto.

Palabras clave: Señoríos. Benedictinos. Cluniacenses. Reserva señorial. Explotación directa. Campesinado. Servidores domésticos. Prestaciones personales.

ABSTRACT: Direct exploitation made up one of the exploitation forms of the Land lords territorial properties in medieval Europe. Throughout the central centuries of this period, this direct exploitation experimented a reduction that accelerated in the $14^{\text {th }}$ Century. However, direct exploitation did not totally disappear. This process is also evident in the Duero river basin, a space in which we see an example of a Cluniac Benedictine seigniory that is defined by the large amount of information concerning it. 
Keywords: Seigneuries. Benedictines. Cluniac Order. Demesne. Direct exploitation. Peasantry. Servants. Boon-works.

SUMARIO: 0 Introducción. 1 El siglo XIII. 1.1 La explotación directa de las tierras de cereal. 1.2 La explotación directa del viñedo. 1.3 Los arrendamientos. 2 El siglo XIV. 3 El siglo XVI.

Los dominios feudales albergaban, como sabemos, tenencias en manos de familias campesinas que debían hacer efectivas rentas a sus señores y recursos territoriales que estos poseían en régimen de propiedad plena -lo que llamaremos «propiedad dominical»- y que podían hallarse sometidos a algún tipo de cesión o bien estar explotados bajo el control directo de sus titulares. Ello nos pone ante la dicotomía explotación directalexplotación indirecta, una dicotomía que parece bastante discutible en ocasiones y que puede provocar equívocos en relación con el grado de implicación personal de los señores en la explotación directa ${ }^{1}$. Pero esta tosca diferenciación puede servirnos como marco para hacer un acercamiento a la realidad de la propiedad dominical que no se hallaba cedida a concesionarios, es decir, a la «reserva», y que podía estar explotada directamente o bien hallarse yerma.

La reserva señorial, especialmente la dedicada al cereal, va a experimentar a lo largo del siglo XIII una reducción que se acelerará en el XIV $^{2}$. Desde esta certeza, queremos aproximarnos a la realidad concreta de este ámbito productivo a través de la consideración de un caso concreto desde los tiempos plenomedievales hasta los inicios de la Edad Moderna. El caso es el del dominio de San Zoilo de Carrión, la principal dependencia de la abadía borgońona de Cluny en tierras ibéricas, que nos ha legado algunos testimonios relevantes en relación con lo antedicho, a diferencia de lo que sucede con San Isidro de Dueñas $^{3}$ y Santa María de Nájera ${ }^{4}$, las otras dos grandes entidades cluniacenses hispánicas.

1 Gavilán, Enrique. El dominio de Párraces en el siglo XV. Un estudio sobre la sociedad feudal. Valladolid: Junta de Castilla y León, 1986, pp. 309-311. También, García Fernández, Ernesto. Santa María de Irache: Expansión y crisis de un señorio monástico navarro en la Edad Media (958-1537). Bilbao: Universidad, 1989, pp. 114 y 115; y PAscua Echegaray, Esther. «Los contextos sociales e institucionales de una economía monástica: Santa María de Montederramo en el siglo XIII". Revista de Historia Económica, 1999, vol. 1, pp. 63-64.

2 Duby, Georges. Economía rural y vida campesina en el Occidente medieval. Barcelona: Península, 1973 , pp. 340-341 y 415-417. En relación con Castilla, Casado Alonso, Hilario. Señores, mercaderes y campesinos. La comarca de Burgos a fines de la Edad Media. Valladolid: Junta de Castilla y León, 1987, pp. 328-341.

3 Reglero de la Fuente, Carlos M. El monasterio de San Isidro de Dueñas en la Edad Media. Un priorato cluniacense hispano (911-1478). Estudio y colección documental. León: Centro de Estudios «San Isidoro", 2005, pp. 130-132, 158-160, 195-196 y 211-212.

4 Cantera Montenegro, Margarita. Santa María la Real de Nájera, siglos XI-XIV. 3 vols. Madrid: Universidad Complutense, 1985. La autora consigna algunas prestaciones personales debidas por campesinos entre los siglos x y xIV, pero no podemos hacernos una idea de la entidad de la reserva monástica a partir de estas informaciones (ibidem, vol. I, pp. 478-483) o de las menciones de domus -y, en algunos casos, de palatium y granja- que aparecen en la documentación entre los siglos XI y XIV (ibidem, vols. II y III, docs. 57, $66,74,151$, etc.). 
JULIO A. PÉREZ CELADA

LA EXPLOTACIÓN DIRECTA DE LA PROPIEDAD DOMINICAL MONÁSTICA

EN LA CUENCA DEL DUERO. LOS CLUNIACENSES

Los cenobios de benedictinos negros no sumisos «feudalmente» a Cluny presentes en los territorios castellano-leoneses tampoco ofrecen, por lo que se refiere a la explotación y entidad de sus tierras propias en tiempos plenomedievales, informaciones análogas a las que brinda la documentación de San Zoilo. Dichas tierras, en cualquier caso, se encuentran mayoritariamente cedidas a renta en el siglo xIV. Por lo que respecta a los benedictinos blancos, que con ciertos matices experimentan análoga circunstancia, sus tierras gestionadas directamente -con frecuencia en el marco de las granjas- se hallan en general mejor documentadas, sobre todo en tiempos tardíos ${ }^{5}$.

Partiremos de un documento del monasterio de San Zoilo de Carrión correspondiente al ańo 1213, expresivo de un momento en el que la explotación directa de sus tierras por parte de los señores aún mantiene una importante vigencia ${ }^{6}$, para llegar a mediados del siglo XVI, cuando dicho modo de explotación, tras dos siglos de atonía, experimenta una cierta revitalización en el dominio del mencionado monasterio.

\section{EL SIGLO XIII}

En otro lugar hemos abordado el proceso a lo largo del que la comunidad radicada en San Zoilo de Carrión se benefició de las donaciones de los miembros de la familia condal de los Banu-Gómez a lo largo del siglo $\mathrm{XI}^{7}$, sin que haya que descartar las de otra procedencia, y, durante el XII y el XIII, de las de nobles, que pusieron en sus manos divisas en villas de behetría, y de monarcas, que hicieron lo propio con varias villas en las que dicha comunidad actuará ejerciendo el señorío exclusivo durante largo tiempo ${ }^{8}$.

En febrero de 1213, Pedro, prior del monasterio de San Zoilo de Carrión y camerario de Cluny en Hispania, ordena realizar un inventario de las posesiones y rentas del cenobio cuyo destinatario es la abadía de San Pedro de Cluny ${ }^{9}$. A través de este

5 Pérez-Embid, Javier. El Císter en Castilla y León. Monacato y dominios rurales (siglos XII-XV). Salamanca: Junta de Castilla y León, 1986; y López García, José Miguel. La transición del feudalismo al capitalismo en un señorío monástico castellano. El abadengo de la Santa Espina (1147-1835). Valladolid: Junta de Castilla y León, 1990. El monasterio de La Espina explota directamente a fines del xvi las tierras y recursos de su extenso coto -que pueden evaluarse con precisión- y, de modo combinado con las cesiones, los de sus granjas (ibidem, pp. 81-87). Ciertamente, documentos como el que utilizara Higounet, Charles. La grange de Vaulerent. Structure et exploitation d'un terroir cistercien de la Plaine de France, XII'-XVe siècles. Paris: S. E. V. P. E. N., 1965, correspondiente al ańo 1248, son excepcionales.

6 Martínez Sopena, Pascual. La Tierra de Campos occidental. Poblamiento, poder y comunidad del siglo X al XIII. Valladolid: Institución Cultural Simancas, 1985, pp. 214-244; y Barón FAraldo, Andrés. Grupos y dominios aristocráticos en la Tierra de Campos oriental. Siglos X-XIII. Palencia: Diputación Provincial, 2006, pp. 405-415.

7 Pérez Celada, Julio A. El monasterio de San Zoilo de Carrión. Formación, estructura y decurso histórico de un señorío castellano-leonés (siglos XI al XVI). Burgos: Universidad, 1997, pp. 81-98. La problemática de la formación del señorío de «abadengo» y sus desarrollos posteriores pueden verse en el reciente trabajo de Martínez García, Luis. «El señorío abadengo en Castilla. Consideraciones sobre su formación y desarrollo (ss. XI-XIv)». Edad Media. Revista de Historia, 2007, vol. 8, pp. 243-277.

8 Sobre el proceso de configuración del patrimonio del monasterio en estos siglos, Pérez CELADA, El monasterio, pp. 81-109.

9 El documento, al que ya hicimos un acercamiento en nuestra tesis doctoral (Pérez Celada, El monasterio, pássim), fue publicado por Bernard, Auguste et Bruel, Alexandre. Recueil des chartes de l'abbaye 
JULIO A. PÉREZ CELADA

LA EXPLOTACIÓN DIRECTA DE LA PROPIEDAD DOMINICAL MONÁSTICA

EN LA CUENCA DEL DUERO. LOS CLUNIACENSES

documento, muy poco usual en nuestro ámbito geográfico en los tiempos en que se fecha, llegarán hasta nosotros valiosas informaciones sobre la entidad y características del dominio monástico a principios del siglo xiII, así como sobre las pautas que guían su gestión, resultando especialmente significativos los datos relativos a la reserva monástica y sus cauces de aprovechamiento ${ }^{10}$, aunque, ciertamente, dichos datos también plantean algunos problemas irresolubles.

\subsection{La explotación directa de las tierras de cereal}

El Inventario de 1213 nos presenta a los monjes de San Zoilo como señores exclusivos o como meros titulares de heredades y derechos señoriales sobre campesinos en 59 lugares situados en el páramo leonés-palentino, la Tierra de Campos y el Campo de Toro, unos espacios que se inscriben en las actuales provincias de Palencia, Valladolid y Zamora.

Para realizar una aproximación al documento, conviene establecer algunos criterios para la selección de las informaciones que nos brinda. En primer lugar, nos referiremos a los lugares de los que se da una información precisa sobre la extensión de las «heredades» -es decir, y en este contexto, de las tierras cerealísticas poseídas por la comunidad en régimen de propiedad plena- y que alcanzan la cifra de $27^{11}$. Dicha extensión se expresa

de Cluny. Paris: Imprimerie Nationale, 1903, vol. VI, pp. 934-940, n. 4.469 bis, pero ha sido objeto de una nueva edición por parte nuestra: Pérez Celada, Julio A. Documentación del monasterio de San Zoilo de Carrión (1047-1300) [en adelante, Documentación I]. Burgos: Eds. Garrido, 1986, pp. 132-138, n.o 80. A ella remitimos al lector. Este documento se mencionará en adelante en el texto como «Inventario de 1213». Hay que decir que el Inventario recoge bajo la dependencia del priorato carrionés el monasterio de San Vicente de Salamanca -que ha experimentado recientemente un importante crecimiento patrimonial y de monjesy la iglesia de Santa Ágata de Ciudad Rodrigo, entidades que nunca estuvieron integradas orgánicamente en la dependencia de San Zoilo y que no volverán a aparecer en su documentación. Si acaso, señalemos que en 1213 San Vicente alberga 12 parejas de bueyes y viñas para 8 cubas, y que Santa Ágata posee magnam hereditatem que se halla en manos de un hijo del rey Fernando II de León.

10 Sobre estos inventarios, Martínez Sopena, Pascual. «Les redevances à part de fruits dans l'Espagne du Nord au Moyen Âge». En Les revenus de la terre. Complant, champart, métayage en Europe occidentale (IX'-XVII siècle). Tèmes journées de l'Abbaye de Flaran (1985). Auch: Comitè Départamental du Tourisme, 1987, p. 77. El Inventario de 1213 recoge información relativa a ingenios molineros, prados o huertos en manos de los monjes. Estos recursos tienen importancia como piezas de la reserva, pero las menciones de huertos y prados en la fuente son muy episódicas y las de molinos solo nos permiten conocer su número, que es de 11. La documentación anterior y posterior permitirá salvar esta carencia, como puede verse en Pérez Celada, El monasterio, pp. 140-165. Asimismo, en Pérez Celada, Julio A. «Horticultura y molinos de agua en el curso medio del río Carrión en la Edad Media». En Papers of the "Medieval Europe Brugge 1997" Conference. An International Conference of Medieval and Lather Archaeology, vol 6, Rural Settlements in Medieval Europe. Brujas, 1997, pp. 271-282; y, del mismo, "La explotación de los recursos hidráulicos en el curso medio del río Carrión en la Edad Media». Publicaciones de la Institución Tello Téllez de Meneses, 2000, vol. 71, pp. 113-133.

11 Son estos: Bahíllo, Becerril de Campos, Castrillo de Macintos, Castrocisneros, Cestillos, Cisneros, San Felices, Frechilla, Fuentes de Valdepero, San Mamés (la heredad de la Cocina), San Martín de los Álamos, San Zoilo de Carrión (la heredad de la Limosna), Paredes de Nava, Riosmenudos, Robladillo, Sauquillo, Trigueros, Valdefuentes, Villorido, Villafrechós, Villahélez, Villalpando, Villanueva del Río, Villarramiel, Villasarracino, Villaturde y Villovieco. 
mediante la fórmula «habemus hereditatem para ' $\mathrm{x}$ ' iuga boum», que se presenta con algunas variantes que no empańan la claridad de su significado. Esta estimación de la extensión de las heredades vinculada a la capacidad de trabajo de los yugos de bueyes nos remite a la yugada, cuya dimensión en los tiempos que consideramos parece ser objeto de consenso, de modo que vamos a atribuirle un valor aproximado de $25 \mathrm{ha}^{12}$. Así, los lugares sobre los que se ofrece una estimación de la superficie de la heredad monástica albergan entre una y ocho yugadas, y la suma total de las mismas en el conjunto de núcleos alcanza las 71, es decir, unas 1.775 ha.

Es necesario aclarar que estas extensiones de tierra no tienen por qué estar siempre puestas en explotación en el momento que consideramos. En el Inventario de 1213, al menos en el caso del patrimonio administrado por la mesa prioral, parece que se tuvo buen cuidado de recoger la presencia "efectiva» de yugos de bueyes allá donde esta se diera, como veremos. El criterio usualmente aplicado fue el de indicar la extensión del terrazgo en yugadas o bien el número de yugos disponible, pero casi nunca ambas magnitudes simultáneamente. Solo en dos casos, Villafrechós y Villalpando, nos consta la existencia de un equipamiento productivo aplicado al terrazgo que previamente se ha evaluado en yugadas. En Villalpando, en efecto, hay cinco yugadas, pero solo dos yugos de bueyes, mientras que en Villafrechós las tres yugadas disponibles están trabajadas por otros tantos yugos de bueyes ${ }^{13}$. Existen, por lo demás, casos en los que la heredad estimada en yugadas no es explotada por los monjes al hallarse arrendada. Esto es lo que sucede con la de Castrillo -que tiene una yugada y se halla, junto con un importante viñedo y los campesinos del lugar, en manos de Sancho Fernández- y con la de Fuentes de Valdepero -que, conteniendo tres yugadas, está cedida a renta, en esta ocasión sin incluir un amplio conjunto de vińas-.

Así pues, solo en cuatro de los 27 casos en que se ofrece la estimación de la superficie de la heredad monástica podemos afirmar que esta se halla explotada, total o parcialmente. Pero ¿qué ocurre con los 23 restantes? La respuesta es ciertamente ardua y nos lleva a hacer algunas discriminaciones en el conjunto de núcleos. En primer lugar, dentro de este grupo hay 10 lugares en los que se registra la presencia de campesinos

12 Clemente Ramos, Julián. La economía campesina en la Corona de Castilla (1000-1300). Barcelona: Crítica, 2003, pp. 53-54, 100 y 105-106. Puede matizarse la extensión convencional que atribuimos a la yugada con Pérez Moreda, Vicente. «Problemas de método en torno al análisis del documento». En García Sanz, Ángel; Martín, José-L.; Pascual, José A. y Pérez Moreda, Vicente. Propiedades del cabildo segoviano. Sistemas de cultivo y modos de explotación de la tierra a fines del siglo XIII. Salamanca: Universidad, 1981, pp. 35-36. El Inventario de 1213 nos muestra la yugada como la extensión que labra un yugo en un ańo en el caso de Villovieco: «habemus hereditatem ad unum iugum boum per annum sufficientem».

13 En 1184 Fernando II y el monasterio realizan una permuta que tiene como resultado la atribución a los monjes de un número indeterminado de vasallos que se han trasladado a Villafrechós desde la cercana Cabañas y que deben hacer para aquellos «tales foros atque seruitium» que en Cabañas. Lo cierto es que el Inventario de 1213 no recoge su existencia, aunque sí la de domos monásticas y derechos sobre las iglesias de Villafrechós que se establecían en la permuta de 1184. Este mismo documento informa de que los monjes, tras desprenderse en favor del monarca de la mayor parte de sus heredades en Villafrechós, conservan en la villa «duas iugatas, quantum duo paria boum per unumquemque annum arare possunt», es decir, una menos que las consignadas por el Inventario de 1213 (PÉrez CELADA, Documentación I, doc. 55). 
dependientes de los monjes, denominados de modo diverso ${ }^{14}$, entre los que tienen una amplia presencia, al igual que en los otros subconjuntos de aldeas que trataremos más adelante, los collacios, que no deben ser entendidos aquí como criados domésticos, sino como campesinos asentados en solares ${ }^{15}$. A ninguno de estos colectivos campesinos se le atribuye la obligación de realizar sernas.

En el grupo de lugares en los que se evalúa la extensión del terrazgo, Becerril, Frechilla, Paredes de Nava, Sauquillo, Villafrechós y Villarramie ${ }^{16}$ albergan domos o casas monásticas, que debemos asimilar a edificios destinados a la gestión de explotaciones directas ${ }^{17}$. Pero, salvo en el caso de Villafrechós, donde, como hemos indicado, la explotación directa se halla a pleno rendimiento con yugos de bueyes aplicados a la misma, los otros núcleos donde hay domos o casas pertenecientes a este subconjunto no disponen, según el documento, de bueyes monásticos y solo en uno hay vasallos, que no realizan sernas. Hay iglesias pertenecientes al cenobio en siete lugares de este grupo en los que no se mencionan casas o domos y que, eventualmente, pudieran desempeñar análoga función a la de estas entidades, pero nada indica que lo hicieran; en los siete hay campesinos dependientes que no están

14 Así, en Bahíllo (collazos), Cestillos (vasallos), Cisneros (collazos), San Felices (16 vasallos), San Mamés (collazos), Riosmenudos (solariegos), Villanueva del Río (vasallos), Villarramiel (vasallos), Villaturde (4 vasallos) y Villovieco (collazos). Nótese que solo en dos casos se ofrece la estimación numérica de los dependientes.

15 La condición de criados domésticos de los collazos constituye, en general, una realidad indiscutible. Sin ánimo de exhaustividad, citemos, en relación con ello, a Martínez García, Luis. «Solariegos y señores. La sociedad rural burgalesa en la Plena Edad Media (ss. XI-XIII)». En Burgos en la Plena Edad Media. III Jornadas Burgalesas de Historia. Burgos: Asociación Provincial de Libreros, 1994, pp. 365-366; y, por tratarse de un trabajo referido al área que nos ocupa, a BARón FARALDo, Grupos y dominios, pp. 413-415. Sin embargo, el Inventario de 1213 muestra a estos elementos como campesinos al frente de pequeñas explotaciones y obligados a pagar infurciones y, en su caso, hacer efectivas sernas. En 1213, el monasterio de San Andrés de Congosto, que la comunidad ha cedido a renta, alberga, de modo diferenciado, collaciis y mancipios. Unos ańos antes nos encontramos con "prestimonium collatiorum» en Cestillos (Pérez Celada, Documentación I, doc. 73). Lo mismo que en San Zoilo de Carrión sucede en San Isidro de Dueñas y Santa María de Nájera, los otros dos grandes dominios cluniacenses hispánicos: Reglero de la Fuente, El monasterio, pp. 155-160, y, sobre todo, Cantera Montenegro, Santa María la Real, donde Diego López de Haro dona en 1200 unos collazos al monasterio, indicando que "collacios damus et concedimus vobis cum suis solariis et omnibus suis hereditatibus et omnibus suis pertinentiis» (vol. II, doc. 102), haciendo lo propio en 1201 con «unum collacium in Torreziella, scilicet Blasco Sanchez, cum solare suo et cum tota hereditate et pertinentia sua» (vol. II, doc. 104); por lo demás, los collazos, cuya condición inicial desconocemos, a los que este monasterio cede onerosamente una serna en Alesón en 1220-1222, verán incrementada en 1239 la prestación debida con la obligación de pagar marzadgas (vol. II, docs. 122, 143 y 152); en fin, los monjes de Nájera poseen en 1249 «tres collazos en Torres, que es en Castilla Vieia, que nos valen de VIII fasta X morabetinos cada anno de renta» (vol. II, doc. 155). Asimismo, los collazos del cenobio navarro de Santa María de Irache parecen sustentar esta misma condición de campesinos al frente de pequeñas explotaciones (García Fernández, Santa María de Irache, pp. 125 y 128).

16 No computamos en este grupo la heredad de la Limosna inmediata al monasterio, que tiene una yugada.

17 Véase, por ejemplo, Martínez Sopena, «Les redevances», p. 89; y Pérez Celada, El monasterio, pp. 230-235. En relación con ello, y sobre la diferencia entre la domus o casa y la granja, MARTínez García, Luis. El Hospital del Rey de Burgos. Un señorio medieval en la expansión y en la crisis (siglos XIII y XIV). Burgos: Eds Garrido, 1986, pp. 123-131. 
JULIO A. PÉREZ CELADA

LA EXPLOTACIÓN DIRECTA DE LA PROPIEDAD DOMINICAL MONÁSTICA

EN LA CUENCA DEL DUERO. LOS CLUNIACENSES

obligados a hacer sernas ${ }^{18}$. Así las cosas, nos encontramos con que hay 23 lugares que, pese a albergar casas o domos en seis casos, iglesias en siete y tenentes campesinos en 10 -solo en Villarramiel coexisten casas y tenentes-, no conocen según el Inventario la presencia de bueyes del monasterio. A las tierras y edificaciones registradas, y para que tuviéramos constancia de que constituyen explotaciones agrarias, habría que añadirles bueyes ${ }^{19}$ y servidores encargados de ellos, ya se trate de mancebos o de yugueros, o la capacidad de los monjes para exigir trabajo compulsivo, y no hay ninguna mención de dichas realidades en estos casos. No habría que descartar, en su caso, el recurso al trabajo asalariado ${ }^{20}$ combinado con el eventual alquiler de bestias ${ }^{21}$, pero el Inventario no ofrece ningún dato al respecto, y tampoco la documentación coetánea.

Nos hallamos, pues, ante la circunstancia de que el Inventario no consigna como puesta en valor de modo explícito una parte relevante de su reserva cerealística en 1213. Un rastreo de la documentación posterior nos permite saber que siete de los 27 lugares sobre los que se ofrece la extensión de la heredad -los cuatro que se hallan explotados y los 23 de los que no se indica nada- no son mencionados en las Cuentas de 1338 y que con posterioridad no serán apeados en los siglos XV y XVI ${ }^{22}$. Otros ocho aparecen mencionados en las Cuentas de 1338 como lugares que devengan rentas al monasterio, pero no serán apeados en las mencionadas centurias, lo cual no tiene por qué significar que los monjes los hayan abandonado ${ }^{23}$. Dos no serán mencionados en las Cuentas de 1338 , pero sí apeados posteriormente ${ }^{24}$. En fin, diez aparecerán en las Cuentas de 1338 como lugares que aportan rentas al monasterio y, asimismo, serán ulteriormente

18 Dentro de este grupo, hay iglesias monásticas en Cestillos, Cisneros, San Felices, San Mamés, Riosmenudos, Trigueros y Villaturde. Con la excepción de Trigueros, hay campesinos dependientes en todos estos núcleos. Fuera de este conjunto está Villalpando, donde hay iglesias monásticas y también dos yugos de bueyes que labran parte de las cinco yugadas disponibles.

19 El Inventario recoge que el monasterium de San Andrés de Congosto se halla arrendado y que su concesionario "tenet nostras uaccas", pero también que «inde habemus boues para (tachado: totas) domos nostras". La tachadura puede que se vincule a la circunstancia que venimos explicando: en bastantes lugares que albergan domos no hay bueyes y en otros que no las albergan solo hay tierras sin bueyes, mientras que los yugos de bueyes «efectivos» solo aparecen consignados en 16 lugares. Martínez Sopena, Pascual. «Espacio y sociedad en Palencia durante los siglos XI y XII». En Enciclopedia del románico en Castilla y León. Palencia. Aguilar de Campoo: Fundación Santa María la Real, vol. I, p. 33, afirma que «en la casa de San Andrés, cercana a Congosto de Valdavia, se criaban las bestias de tiro que cubrían las necesidades de todas las explotaciones labrantías del cenobio». A tenor de lo que estamos viendo, esta afirmación debe ser matizada.

20 Clemente Ramos, La economía campesina, pp. 86-92.

21 Moreta Velayos, Salustiano. Rentas monásticas en Castilla: Problemas de método. Salamanca: Universidad, 1974, p. 90, nos muestra al cillero de Santo Domingo de Silos alquilando yuntas de animales en 1337.

22 Sobre esta fuente trataremos más adelante. Baste decir que en dichos lugares -Castrocisneros, San Martín de los Álamos, Sauquillo, Valdefuentes, Villafloridio (Villorido), Villahélez y Villovieco- poseen los monjes en 1213 heredades de solamente dos yugadas, salvo en Villovieco, donde la heredad es de una yugada. Es decir, que, tratándose de terrazgos más bien modestos, puede que estén condenados a su ulterior segregación del dominio.

23 Son estos: Cisneros, San Felices, Fuentes de Valdepero -cuyo terrazgo está arrendado en 1213-, Riosmenudos, Villafrechós, Villalpando, Villarramiel y Villasarracino.

24 Se trata de Castrillo de Macintos, cedida a renta en 1213, y de Becerril de Campos. 
JULIO A. PÉREZ CELADA

LA EXPLOTACIÓN DIRECTA DE LA PROPIEDAD DOMINICAL MONÁSTICA

EN LA CUENCA DEL DUERO. LOS CLUNIACENSES

$\operatorname{apeados}^{25}$. Los apeos de los siglos XV y XVI recogen, por lo demás, núcleos que hasta el momento de su realización no han aparecido nunca en la documentación o que solo lo han hecho en el momento del acceso monástico a ellos, pero no son mencionados ni en el Inventario de 1213 ni en las Cuentas de $1338^{26}$.

Existe, por otro lado, un grupo de 16 lugares -todos ellos bajo la administración prioral y a los que habría que restar el monasterio de Congosto, que se halla arrendado- en los que los monjes poseen, según el Inventario, parejas de bueyes aplicadas a la explotación directa de sus tierras. El número de dichas parejas es variado y oscila entre la única que poseen en Villasirga y las 18 adscritas a la domo de Toro y sus dependencias ${ }^{27}$. Cuando existen bueyes aplicados al trabajo en las tierras monásticas, se recurre a la expresión «sunt ibi modo ' $\mathrm{x}$ ' iuga boum cum omni aparatu» o a variantes de la misma. Diez de estos 16 lugares albergan explícitamente domos, es decir, edificios dedicados a la gestión de la explotación directa ${ }^{28}$ a los que se vincularían servidores domésticos -yugueros o mancebos- que solo aparecen mencionados en el caso del monasterium y las domos de San Andrés de Congosto, y ello porque, hallándose arrendados, el Inventario estipula las condiciones del mantenimiento del equipo humano por el arrendatario: «dales sal et soldadas a los mancipios et pan et conducho». No obstante, sabemos de la existencia de «homines de palatio» en Villafrechós -que cuenta con domos en 1213- en $1184^{29}$. En

25 Son: Bahíllo, Cestillos, Frechilla, San Mamés, Paredes de Nava, Robladillo, Trigueros, Villanueva del Río y Villaturde. A este conjunto cabe añadir la heredad para un yugo que gestiona la Limosna en Carrión, diferenciada del grueso de las tierras en el lugar, controladas por el prior mayor.

26 Los núcleos que aparecen en los apeos por vez primera son Ferreros, Villamoronta, Bustillo de Potroviejo, Bercianos, Lomas y Terradillos. Los que están documentados en el momento de su acceso a ellos por los monjes son Bárcena (año 1416), Villanueva de los Nabos (1208), Quintanilla de la Cueza (1129), Villanueva del Rebollar (1123) y Santa María del Páramo (1446). Pérez Celada, El monasterio, pp. 99-125 y 334-350.

27 Enumeramos dichos lugares y, entre paréntesis, indicamos el número de yugos de bueyes existente en cada lugar: Aguilar de Campos (4), Arconada (4), Autillo (2), Cardeñosa (7), Congosto (3), Frómista (3), Gañinas (3), Toro (18), Villabaruz (2), Villafrechós (3), Villalpando (2), Villamuera (2), Villasirga (1), Villibańe (2), Volpejera (2) y monasterio de San Zoilo (8). Podría establecerse una escala comparativa con las explotaciones campesinas individuales que, en lo referente al cereal y en términos «medios», se corresponderían con una yugada y un yugo cada una de ellas, así que en dichos términos cada yugo o yugada monásticos podría corresponderse con una explotación familiar adecuadamente dotada; aunque lo cierto es que las variaciones en la dotación de las explotaciones son múltiples y que, por decirlo con palabras de Clemente Ramos ( $L a$ economía campesina, p. 40), «la explotación media es más una realidad conceptual que estadística». Por lo que se refiere a las explotaciones directas monásticas, las granjas y casas cistercienses ofrecen dotaciones de bueyes variadas que se mueven en unos límites coincidentes con los de las domos de los monjes negros: en el siglo XIII hallamos cinco yugos en la granja de Cañizo, perteneciente a Carracedo (Pérez-Embid, El Císter en Castilla y León, p. 145); nueve en la casa de Anayalfonso y dos en las casas de Gumiel, pertenecientes ambas al monasterio de San Pedro de Gumiel de Hizán y que son objeto de cesión (ibídem, p. 315); cinco en la explotación gallega de Vilardois, perteneciente a la granja de Gorjá (Portela Silva, Ermelindo. La colonización cisterciense en Galicia (1142-1250). Santiago de Compostela: Universidad, 1981, p. 96); 14 en la asimismo gallega de Genestoso (ibidem, p. 97), etc.

28 Son: Arconada, Congosto -el monasterium que está arrendado con todas sus pertenencias en este momento-, Frómista -que es el monasterio y domus de San Martín-, Gañinas, Toro -donde se halla la domo de San Pelayo-, Villamuera, Cardeñosa, Villaverde, Villafrechós y el propio monasterio de San Zoilo.

29 Pérez Celada, Documentación I, doc. 55. 
los seis lugares con presencia de bueyes en los que no se mencionan domos o casas, hay iglesias bajo el patrocinio de los monjes que, a diferencia de las cautelas expresadas más arriba en relación con los lugares donde no se consigna la existencia de bueyes, debían de ser, además de espacios de culto, centros de la explotación directa ${ }^{30}$. Con la excepción de Congosto, el Inventario no menciona servidores, aunque en el caso del centro del dominio, el monasterio de San Zoilo, la documentación posterior recoge en 1240 la presencia de "dos iugueros»; además, sabemos de la existencia de yugueros labrando las heredades adscritas a la domo de San Pelayo de Toro y ubicadas en Pozoantiguo en $1223^{31}$. Estos datos son relevantes, porque nos permiten pensar en la presencia de yugueros en diversos lugares del dominio en 1213 que podría complementar la de mancebos $\mathrm{u}$ "homines de palatio» presentes en otros.

Hay que insistir, siguiendo con la consideración de la extensión de las heredades monásticas, en la circunstancia de que el Inventario es muy preciso a la hora de recoger la información relativa a la mesa prioral, en consonancia con el hecho de que sea el titular de esta quien emite el documento, y que todas las noticias referidas a las mesas gestionadas por los oficiales -Sacristanía, Limosna, Cocina, Vestuario, Enfermería y Priorazgo de Claustra- son muy escuetas. En estos términos, la mesa del prior solo inventaría seis lugares en los que se indica meramente la superficie del terrazgo ${ }^{32}$ y algún otro en el que se hace una simple mención de la propiedad de tierras, mientras que las mesas de los oficiales nunca consignan bueyes «reales» en sus heredades ni tampoco prestaciones personales aplicadas a ellas o a otro ámbito productivo y sí nos muestran hasta 18 lugares en los que poseen tierra estimada en yugadas. De ellos, cinco albergan domos o casas, y otros cinco iglesias ${ }^{33}$. Asimismo, los oficiales tienen vasallos en al menos cinco lugares, collazos en tres y dependientes que, aunque no se mencionan, han de hallarse asociados al señorío exclusivo sobre Valcabado -administrado por el Vestuario- en uno; en ningún

30 Los lugares donde hay bueyes e iglesias, pero no domos, son: Aguilar de Campos, Autillo, Villabaruz, Villalpando, Villasirga y Villibañe. Ver, sobre la eventual funcionalidad productiva de las iglesias o monasterios, Reglero de la Fuente, El monasterio, p. 131; y Estepa Díez, Carlos. «Propiedad y señorío en Castilla (siglos XIII-XIV)». En Señorio y feudalismo en la Península Ibérica (ss. XII-XIX). Zaragoza: Institución Fernando el Católico, 1981, vol. I, pp. 382 y ss.

31 Pérez Celada, Documentación I, doc. 101; y Reglero de la Fuente, Carlos. Cluny en España. Los prioratos de la provincia y sus redes sociales (1073-ca. 1270). León: Centro de Estudios e Investigación «San Isidoro», 2008, p. 452. Sobre el yuguero, GIBERT, Rafael. «El contrato de servicios en el derecho medieval español». Cuadernos de Historia de España, 1951, vol. XV, pp. 65-70; Martín CeA, Juan Carlos. "Una pequeña contribución al conocimiento del campesinado castellano: el yuguero». En El pasado histórico de Castilla y León. Burgos: Junta de Castilla y León, 1983, vol. I, pp. 101-112; Martínez Sopena, «Les redevances», p. 83; y Reglero de la Fuente, El monasterio, p. 211.

32 Son: Bahíllo, Castrocisneros, Cisneros, Riosmenudos y Villovieco. La heredad monástica en Castrillo, de una yugada, se halla cedida a renta.

33 Concretamente, albergan domos Becerril, Frechilla, Paredes de Nava, Sauquillo y Villarramiel. Iglesias en lugares con la extensión de la tierra estimada hay en Villaturde, San Felices, Cestillos, Trigueros y Fuentes de Don Bermudo, lugar, este, donde hay viñas para una cuba; pero también hay iglesias en Valcabado -villa bajo la jurisdicción exclusiva del monasterio-, que no sabemos si alberga propiedad dominical, mientras que en Arconada hay una heredad de extensión desconocida de la Sacristanía -recordemos que la principal la gestiona el prior mayor- y en Mayorga el Prior de Claustra tiene un huerto y una vińa. 
caso consta que deban hacer sernas ${ }^{34}$. No cabe sino hacerse algunas preguntas a las que responder afirmativamente sería en verdad aventurado: ¿solo el prior controlaba a campesinos sujetos a sernas?, ¿'solo el prior administraba heredades trabajadas por bueyes propiedad del monasterio?, ¿los oficiales monásticos tenían adjudicadas tierras de cereal con al menos 51 yugadas de extensión en más de veinte lugares donde solo estaban en disposición de obtener cuatro maravedís por el arrendamiento de la heredad de Mazuecos y 35 por el de los bienes innominados y los huertos de San Sebastián de Liébana?

Interesa resaltar que el Inventario menciona la existencia de tenentes campesinos en siete de los 16 lugares en que se indica el número de bueyes monásticos, denominándolos collazos $^{35} \mathrm{y}$ homines, una voz, esta, que sirve a los monjes para referirse a los campesinos que habitan en las villas situadas bajo su jurisdicción ${ }^{36}$. En cinco de estos siete lugares los campesinos han de realizar sernas, que se suman a la labor que se realiza con los bueyes monásticos, salvada la circunstancia de la posible dedicación de aquellas al viñedo. Resulta relevante el caso de Arconada, donde los collazos monásticos realizan cada uno 24 sernas anuales ${ }^{37}$; en Villamuera y Villaverde de Volpejera los homines hacen sendas series de 12 prestaciones anuales; por su parte, los homines de Gañinas realizan tres sernas anuales y los collazos de Cardeńosa están obligados a un número de prestaciones indeterminado. Estos campesinos trabajarían en tierras distintas de las labradas por los bueyes monásticos. En fin, dos lugares en los que el monasterio no exige prestaciones personales, pero en los que tiene más tierra de la que explota, son Villabaruz, donde posee dos yugos y «hereditatem magnam», y Villalpando, en el que, como señalamos antes, tiene dos yugos, pero la heredad abarca cinco yugadas.

La mención de prestaciones personales exclusivamente en los lugares administrados por la mesa prioral nos hace pensar que su número podría ampliarse si tuviéramos más

34 Son estos: Villaturde (cuatro vasallos), Villanueva (vasallos), Arconada (vasallos, aunque los dependientes del prior mayor son llamados collazos), Cestillos (vasallos), Villarramiel (vasallos), Calzadilla (collazos), San Mamés (collazos), Riberos de la Cueza (collazos) y Valcabado (villa tota nostra).

35 Son: Arconada, Cardeñosa, Congosto y Villasirga. En las donaciones previas a la realización del Inventario, el monasterio recibió collazos que parece que eran servidores domésticos, dado que en algunas cartas se diferencia a los collazos de los solares populatos e impopulatos, pero en 1213, como hemos dicho, los collazos no son sino tenentes campesinos, y en el Becerro de las Behetrías de mediados del siglo xiv sus «sucesores» ya no reciben esta denominación y no tienen ninguna consideración diferenciada de los demás campesinos de abadengo ubicados en otros lugares. Por lo demás, es muy interesante que en un documento de 1203 se hable de collazos en Cestillos -además de mencionarse por separado «solares populatos et non populatos"-y de "prestimonium collatiorum» (Pérez CeladA, Documentación I, n. ${ }^{\circ} 74$ ) y que en el Inventario de 1213 los dependientes monásticos en el lugar sean denominados exclusivamente uasallos.

36 Hay homines en Gańinas, Villamuera y Villaverde de Volpejera. En conexión con lo dicho en la nota que antecede, el monasterio recibió las villas de Gañinas, Revenga y Villaverde de Volpejera de Alfonso VIII en 1181 con collatiis y con «solaribus populatis et heremis» (Pérez Celada, Documentación I, n. ${ }^{\circ}$ 52), resultando que en la primera y en la tercera los dependientes son denominados simplemente homines en el Inventario de 1213.

37 El caso de Arconada, sobre el que volveremos, resulta de interés, por cuanto el elevado número de sernas anuales que debe realizar cada collazo le exime de hacer efectiva cualquier otra prestación, aunque también determina que no sea mantenido a costa de los monjes mientras realiza sus labores. Sobre esta circunstancia, GARcía DE CoRTÁzAR, José Ángel. La sociedad rural en la España medieval. Madrid: Siglo XXI, 1988, p. 102. 
información sobre los lugares adscritos a los oficiales ${ }^{38}$. Dependientes sometidos a sernas, o a otras prestaciones laborales, aparecen en 11 núcleos. La frecuencia de las sernas propiamente dichas oscila entre las 24 anuales que deben hacer los collazos de Arconada y los dependientes de Revenga -donde hay "multam hereditatem»- y las tres de los homines de Gañinas y los collazos de Calzada de los Molinos, siendo la más común las 12 anuales que deben hacer efectivas los dependientes de Villamez -donde no se consigna la existencia de tierra cerealística o viñedo monásticos- y los homines de Villaverde de Volpejera y Villamuera ${ }^{39}$. Los lugares en que se hacen sernas, excepto Cardeñosa -en la que no consta su número-, Arconada y Calzada, son de señorío exclusivo de los monjes ${ }^{40}$. Por lo demás, los monjes exigen a sus collazos en Villamuera 30 carros de heno -además de las 12 sernas convencionales-, probablemente recogidos en sus "pratis bonis» de dicha villa; y a sus homines de Lobera la recolección y entrega en el monasterio de carros de leña y heno procedentes asimismo de los recursos controlados por la institución en el lugar; así como carros de cepas a los dependientes de Villarmienzo y «carros de ligna» a los collazos de las villas de la «terra Sancti Romani», de quienes según el Inventario obtienen también infurciones, una circunstancia que resulta peculiar - pues la presencia de San Zoilo en este área no se documenta nunca- y que habrá que relacionar con el carácter cluniacense, y por ende sujeto a la autoridad del camerario carrionés, del monasterio de San Román de Entrepeñas ${ }^{41}$. Estas prestaciones laborales vinculadas a la recolección de heno y leña y a su transporte permitían a los monjes el aprovechamiento de fuerza de trabajo campesina en lugares, como los de la «terra Sancti Romani», donde no poseían tierra de cultivo o donde, como en Lobera, habían arrendado la que tenían pero poseían otros recursos. Recurriendo a sus dependientes de los espacios septentrionales para proveerse de leña y al menos de parte del alimento para sus bueyes en el centro del dominio, los monjes se beneficiaban de la complementariedad económica del ámbito centro-meridional y del septentrional del espacio que consideramos ${ }^{42}$.

Las prestaciones laborales para los monjes se reducen mucho a lo largo de las décadas siguientes: así, según el Becerro de las Behetrías, solo Arconada presenta a mediados del siglo XIV la misma dotación de trabajo compulsivo que en 1213, mientras que, en el mismo momento, los dependientes de Villamuera solo hacen cuatro sernas, cuando en 1213 hacían doce ${ }^{43}$. Ninguno de los restantes lugares recogidos por el Becerro de las

38 Pero no debemos perder de vista que, a estas alturas, la contracción de las sernas constituye una circunstancia generalizada (MARTínez SopenA, «Les redevances», p. 86).

39 Sobre la frecuencia de las prestaciones, entre otros, GARCía de CoRTÁzAR, La sociedad rural, p. 102.

40 En 1352, el Becerro de las Behetrías nos presenta a Arconada bajo el señorío compartido de San Zoilo y San Román de Peñas (Martínez Díez, Gonzalo. Libro Becerro de las Behetrías. Edición y estudio crítico. León: Centro de Estudios e Investigación «San Isidoro», 1981, vol. I, pp. 309-310).

41 En 1338 la mesa prioral gasta en leña 720 maravedís al año, sin que se documente la recepción de este producto a título de renta (Pérez Celada, Julio A. Documentación del monasterio de San Zoilo de Carrión (1301-1400) [en adelante, Documentación II]. Burgos: Eds. Garrido, 1987, n. ${ }^{\circ}$ 215, p. 84). Sin embargo, en el último apartado de este trabajo veremos cómo a mediados del siglo xvi los monjes compran leńa, pero también reciben 30 carros de la misma como renta.

42 Martínez Sopena, «Espacio y sociedad en Palencia», p. 33.

43 Martínez Díez, Libro Becerro, vol. I, pp. 309-310 y 327-328. En ambos lugares las sernas se aplican en 1352 al terrazgo cerealístico, puesto que deben hacerse con los bueyes de los dependientes; en 
Behetrías donde los monjes podían exigir sernas en 1213 las realiza ya en el momento de su confección. En cualquier caso, insistamos, no hay que descartar que en 1213 -o en años posteriores- se realizara, cuando menos, alguna prestación más aparte de las consignadas ${ }^{44}$.

En fin, hechas estas consideraciones, conviene intentar una cuantificación aproximativa de la reserva cerealística del monasterio a principios del siglo XiII. Considerando que las tierras evaluadas explícitamente en yugadas nos ofrecen 71 de estas, y que hay 56 yugos de bueyes trabajando en otras cuya extensión no se indica -no computamos aquí los cinco yugos de bueyes de Villalpando y Villafrechós, que trabajan en heredades de extensión conocida-, si suponemos que estos últimos equivalen a yugadas efectivas -aunque no tienen por qué labrar toda la tierra disponible en los respectivos núcleos-, nos encontramos con al menos 127 yugadas, es decir, unas 3.175 ha. Ahora bien, hay otros nueve lugares en los que se consigna la mera posesión de terras o hereditatem, sin ninguna especificación sobre su extensión o equipamiento animal, resultando que, por ejemplo, en Revenga de Campos, donde se dice que hay "multam hereditatem», los dependientes han de hacer 24 sernas anuales, y que en Villabaruz hay, como decíamos, «hereditatem magnam», pero solo dos yugos. Por lo demás, hay otros 12 lugares en los que no se indica la posesión de tierras o heredades, pero en dos de ellos, Calzada de los Molinos y Villamez, los dependientes hacen, respectivamente, tres y 12 sernas anuales, lo que indica la existencia de una dotación territorial monástica, circunstancia que, en el caso de Villamez, confirman, como veremos, las Cuentas de 1338. Así pues, a nadie se le escapa que esas aproximadamente 3.175 ha de la reserva cerealística que conocemos de modo más o menos explícito habrían de incrementarse ampliamente a tenor de las informaciones que nos brindaría un mayor celo de los monjes a la hora de evaluar su patrimonio en un número importante de lugares.

\subsection{La explotación directa del viñedo}

Las estimaciones cuantitativas que, al menos parcialmente, hemos realizado respecto a las tierras de cereal no van a hallar aquí un cumplimiento satisfactorio. Como hemos indicado, la fuente consigna 59 lugares, resultando que en 31 de ellos hay viñas propiedad de los monjes. En 16 de ellos se ofrece la estimación de la producción que puede obtenerse de los viñedos mediante las expresiones «uineas para ' $x$ ' cubas» $y$, en un caso, «uineas para V dolia». No estamos en condiciones de estimar la capacidad del dolium, y lo mismo nos ocurre con las cubas del Inventario. Suponiendo en principio que estas contienen un gran volumen, no responden, que sepamos, a un valor estándar en este momento y espacio. Tampoco podemos saber si en la fuente se considera equivalente la capacidad

\footnotetext{
Villamuera, sobre ello volveremos, los vecinos deben hacer sernas de siega u otras labores en los siglos XV, XVI y XVII (Pérez Celada, El monasterio, pp. 138, n. 31, y 216).

44 En el arrendamiento de la jurisdicción del barrio de San Martín de Frómista en 1325 (PÉREZ Celada, Documentación II, doc. 193) hay una referencia a «las sernas que ouieren a dar» sus vecinos, una información que no aparece en el Inventario de 1213 y tampoco en el Becerro de las Behetrías.
} 
de la cuba a la del dolium ${ }^{45}$. La entidad de los vińedos oscila entre los que pueden rendir ocho cubas en los terrenos adscritos a la casa de Toro y los que podrían llenar uno o dos de estos recipientes en la mayoría de los lugares, con los valores intermedios de cuatro cubas en Aguilar de Campos y Villafrechós; por otra parte, cuando la estimación se hace en dolia, la fuente se limita a indicar, sin evaluar su extensión, los recipientes que alberga una explotación -5 en el caso de Frómista, Villamuera y Cardeñosa de Volpejera, 10 en el de Villalumbroso ${ }^{46}$, 15 en el del monasterio de San Zoilo ${ }^{47}$, donde se dice que en la última vendimia se llenaron todos- o, solo en una ocasión, los que podrían llenarse con el vińedo disponible -las «uineas para V dolia» de Villibañe-. En el caso de Castrillo se indica que hay "uineas para tres carros», mientras que en el de San Felices se dice que hay «VII aranzadas de uineas» -unas $3 \mathrm{ha}-$. En siete casos encontramos menciones imprecisas de uineis, uineas, uineis bonis et multis, uineis paucis o una uinea. Los 28 lugares en los que no se asientan vińas monásticas están ampliamente dispersos, resultando que 15 de ellos se hallan al norte de Carrión de los Condes, en unas áreas, en principio, menos idóneas que las del Sur para la viticultura; ocho, al sur del monasterio; tres, en casi su misma longitud geográfica, y dos, en ubicación desconocida. A nadie se le escapa, en fin, que la extensión de la reserva monástica se vería sustancialmente incrementada si a la superficie de las tierras de cereal se sumara la de las vińas, que, a tenor de los recipientes que pueden ocuparse con sus producciones, era importante.

Resulta de interés considerar el régimen de explotación de estos viñedos. El análisis del libro de las Cuentas de 1338 reveló en su día que las entidades monásticas explotaban de modo directo la mayor parte del viñedo que poseían y no se hallaba «empeñado» ${ }^{48}$. En 1213 el modo de explotación de las viñas del monasterio de San Zoilo era el directo, aunque no tenemos por qué pensar que todas estuvieran cultivadas, al igual que sucedía con las heredades de cereal. En estos momentos, el viñedo se halla más o menos estrictamente organizado en pagos en esta región, aunque nuestra fuente nada indica al respecto ${ }^{49}$. Por lo demás, conviene indicar que los monjes poseen domos o casas en 11 lugares donde también hay viñedo de su propiedad, varios de los cuales -Toro, Villafrechós, Villalumbroso, Villamuera, Frómista o el propio monasterio de San Zoilo- son los considerados en la fuente como los mejor dotados de este recurso. Salvo

45 La documentación medieval del noroeste peninsular nos muestra una variedad de cubas de entre 12 y 50 modios -es decir, de entre 3 y $12,9 \mathrm{~m}^{3}$, o bien de entre algo más de 3.000 y 12.900 litros-, según indican Varela Sieiro, Xaime. Contribución ó estudio do léxico da documentación latina altomedieval do noroeste peninsular. Santiago de Compostela: Universidad, 2000, pp. 284, 285 y 287; y Fernández Corral, Celia. Léxico del mundo rural y costumbrista en la documentación medieval latina del reino de León (775-1230). León: Universidad, 1999, p. 441. Sobre el dolium, esta última nos dice que tiene a veces una cierta identidad con la cuba (ibidem, pp. 442-443). En relación con el valor del modio, Clemente Ramos, La economía campesina, pp. 21-22.

46 En los casos de Villamuera y Villalumbroso se dice además que hay uineis multis et multis y uineas multas et bonas, respectivamente.

47 En 1240 -Pérez Celada, Documentación I, doc. 101- consta la existencia, entre los excusados monásticos de pechos regios, de un uinnadero o guarda de las viñas explotadas directamente cerca del cenobio.

48 García GonzÁlez, Juan José. Vida económica de los monasterios benedictinos en el siglo XIV. Valladolid: Universidad, 1972, pp. 76-78; y Moreta Velayos, Rentas monásticas, pp. 88-89.

49 Martínez Sopena, La Tierra de Campos occidental, pp. 545-546. 
en los casos de Cardeñosa y Villamuera, en ninguno de los lugares con viñedo exigen los monjes sernas a sus dependientes ${ }^{50}$, por lo que nos hallamos ante la circunstancia de que la explotación vitícola ha de realizarse prioritariamente mediante el recurso a mano de obra doméstica o asalariada ${ }^{51}$. Por lo demás, es significativo el hecho de que, habiendo arrendado los monjes sus heredades en Villalumbroso y Fuentes de Valdepero, conserven las vińas al margen de la cesión, lo que nos indica su interés por controlarlas directamente.

\subsection{Los arrendamientos}

En 1213 las cesiones a renta de bienes monásticos tienen una considerable dimensión, aunque muy lejos aún de la que alcanzarán en el siglo XIV y los siguientes. Ya desde mediados del siglo XII, los titulares de dominios eclesiásticos en esta zona transferirán el disfrute de importantes posesiones a personas particulares de condición frecuentemente encumbrada $^{52}$. En el ańo mencionado, los monjes han depuesto, en condiciones variables de duración, el dominio de algunos componentes de su patrimonio que se distribuyen por 12 lugares. Es preciso distinguir entre las cesiones que tienen un carácter prestimonial y las que remiten al pago de una renta como contraprestación de la cesión. Teniendo en cuenta que en las cesiones en prestimonio, aunque no pueda hablarse propiamente de gratuidad, se realizan sin que medie la entrega de renta en la generalidad de los casos aunque a veces constituyen el pago de una deuda contraída previamente-, parece que en las realizadas por los monjes de Carrión nos hallamos en casi todos los casos ante cesiones de carácter arrendaticio y en todo caso oneroso ${ }^{53}$. Estas cesiones presentan una notable diversidad en cuanto a los concesionarios, las condiciones y el objeto de las mismas. Así, vemos que a veces se cede todo un complejo productivo e institucional que incluye al

50 En Cardeñosa, los collazos hacen sernas para los monjes en número indeterminado. En Villamuera, donde según el Inventario poseen «uineis bonis et multis», se realizan 12 sernas en 1213, por lo que no cabe descartar que algunas se destinen al viñedo, aunque en el Becerro de las Behetrías de 1352 las cuatro anuales que se consignan están vinculadas al trabajo con bueyes (Martínez DíEz, Libro Becerro, t. I, pp. 327-328). Estas prestaciones serán conmutadas en 1451 por la entrega de dos cántaras de mosto por cada campesino -quien no tenga vińas ha de entregar leña- y 20 peones anuales a realizar por el colectivo de dependientes en la siega u otra labor; a mediados del siglo XVI, como veremos más adelante, el monasterio obtendrá en el lugar vino de sernas (Pérez Celada, El monasterio, p. 216). García González, Juan José. "Rentas en trabajo en San Salvador de Oña: las sernas (1011-1550)». Cuadernos Burgaleses de Historia Medieval, 1984, vol. I, pp. 178-181, muestra que en el dominio de San Salvador de Ońa se produjo un incremento de ciertas prestaciones personales y el tránsito de una orientación cerealística de las mismas a otra vitícola entre los siglos XIII y xv. En fin, el caso de Arconada es interesante: no alberga viñedo de los monjes según el Inventario y tampoco lo mencionan las Cuentas de 1338, pero a mediados del siglo XIV el Becerro de las Behetrías nos dice que los vasallos de San Román de Peñas -que comparte con San Zoilo el dominio del lugar- «fazen sernas al labrar e al vendimiar» en número de cinco por cabeza (Martínez Díez, Libro Becerro, t. I, pp. 309-310).

51 Véanse los gastos que realizaban los monasterios, salvo el de San Zoilo de Carrión, para el cultivo del viñedo en 1338 en García González, Vida económica, p. 78.

52 Martínez Sopena, La Tierra de Campos, p. 264.

53 Estepa Díez, «Propiedad y señorío», p. 379, indica que desde la primera mitad del siglo XiII el gran arrendamiento va sustituyendo al prestimonio. 
JULIO A. PÉREZ CELADA

LA EXPLOTACIÓN DIRECTA DE LA PROPIEDAD DOMINICAL MONÁSTICA

EN LA CUENCA DEL DUERO. LOS CLUNIACENSES

campesinado dependiente, como en el caso del monasterio de San Andrés de Congosto, cuyo concesionario, Martín de Aviñante, paga 300 áureos (maravedís de oro) al año; el de Castrillo, en manos de Sancho Fernández, que paga vitaliciamente, «ad procurationem faciendam», tres áureos al ańo; o el de Santa Cruz de Cea - una aldea de señorío exclusivo de los monjes en este momento, pero que ya no lo será en 1352-, que está en manos de Alfonso Téllez, del linaje de los Girón, por 40 áureos al año.

En lo que respecta a cesiones a los colectivos de campesinos dependientes -que prefiguran las frecuentes operaciones bajomedievales y modernas de este tipo-, encontramos el caso de Lobera, donde el objeto de la cesión son los molinos y las sernas -entendidas aquí como tierras propiedad de los monjes-, aunque un personaje vinculado a este lugar, «don Micael, el marino» (sic), ha de pagar a los monjes 14 maravedís anuales en concepto desconocido; asimismo, en Villalumbroso los collazos han arrendado la heredad monástica por 30 cargas de pan mediado.

Nos encontramos en otros seis lugares con cesiones de propiedades monásticas a personas desconocidas y a cambio de cantidades de dinero o de productos. Estas cesiones a veces incluyen toda la heredad monástica en un lugar, como sucede en Fuentes de Valdepero o Mazuecos de Valdejinate; en otras, a la heredad se suman las vińas, como vemos en Añoza, y otras, en fin, se limitan a algunos de los bienes que poseen los monjes en un lugar, como es el caso de Villabaruz y Villarmienzo -en la que un clérigo disfruta de la serna, es decir, las tierras de los monjes-. En fin, hay casos -los de San Sebastián de Liébana, el monasterio de San Juan de Aguilar y Villagonzalo- en los que no consta lo cedido ${ }^{54}$.

\section{EL SIGLO XIV}

Al llegar el año de 1338, cuando se realizan las conocidas cuentas de los monasterios de la Provincia Benedictina de Toledo ${ }^{55}$, a las que nos atendremos ahora, encontraremos las tierras de la reserva monástica en situación de cesión a renta, cuando no de "empeño". Los receptores de las cesiones a renta nos resultan casi siempre desconocidos, pero entre ellos cabrá que conceder una presencia relevante a esos arrendatarios/señores que se convierten en intermediarios entre los campesinos y la comunidad monástica ${ }^{56}$.

La cesión generalizada de las tierras de cereal se desprende, entre otras cosas, de que las Cuentas no consignen gastos en simiente o en labores agrícolas. Incluso «el pie del monasterio», que renta 100 cargas de pan mediado, está «dado a quinto e quarto de pan», una modalidad de cesión por la que la institución recibe entre el $20 \%$ y el $25 \%$ de la cosecha, en función de la diferente calidad de las tierras ${ }^{57}$.

54 Sobre las concesiones de bienes monásticos en las condiciones que describimos en este apartado, Martínez Sopena, La Tierra de Campos, pp. 264-273; y Reglero de la Fuente, El monasterio de San Isidro de Dueñas, pp. 160-162.

55 Transcritas por García GonzÁlez, Vida económica, pp. 129-247.

56 Estepa Díez, "Propiedad y señorío», pp. 376-390 y 418-419; Martínez García, "El señorío abadengo", pp. 268-273; y Pascua Echegaray, «Los contextos sociales», pp. 81-86.

57 Martínez Sopena, «Les redevances», pp. 84 y 89. 
Arconada y Villamuera constituyen sendas excepciones. En la primera, los monjes han de entregar en 1338 al concejo del lugar 10 cargas de trigo -entendemos que en concepto de simiente para la explotación directa-, resultando que el lugar renta 35 cargas de pan. En 1352, los dependientes con bueyes deben hacer una serna cada quince días para el monasterio, igual que en 1213; esta circunstancia quizá se plasme en la recepción de al menos parte de esas 35 cargas de pan en $1338^{58}$. De Villamuera obtiene el monasterio 24 cargas de trigo en 1338, resultando que en 1352 los dependientes propietarios de bueyes hacen cuatro sernas al ańo y que las rentas señoriales que pagan son dinerarias ${ }^{59}$. En este sentido, hay que indicar que la fuente de 1338 no diferencia con frecuencia el origen de las distintas partidas de ingresos, por lo que no es imposible que el producto del trabajo compulsivo de los campesinos de estos dos lugares se impute al concepto renta.

Pero, en definitiva, las heredades monásticas que hacía poco más de un siglo se explotaban directamente -siempre que ello fuera factible-, se hallan ahora fuera del control directo de la comunidad, en unos casos porque han sido cedidas a renta y en otros porque, habiéndolo sido probablemente también con anterioridad, están en situación de «empeńo». De todos modos, el peso que, frente a los ingresos devengados por la cesión de la propiedad dominical, tienen los tributos decimales y las rentas derivadas del dominio señorial es muy importante, ya que de otro modo resulta inexplicable la desproporción entre la capacidad productiva de muchas heredades monásticas en 1213 y los ingresos en cereal obtenidos en los lugares en los que estas se hallan ubicadas en 1338, como puede verse, por ejemplo, en los casos de Frómista, Villafrechós o Aguilar de Campos $^{60}$. El instituto que tratamos se atiene, por lo demás, a las pautas gerenciales del

58 En Arconada tenían también los monjes participaciones decimales que conservan en el siglo XVI, pero que no consignan explícitamente las Cuentas de 1338, aunque los 140 maravedís que ingresa la Sacristanía en el lugar quizá tengan ese origen -PÉrez Celada, El monasterio, p. 201 y Documentación II, p. 88-. En el siglo xvi, el monasterio recibe trigo y cebada en concepto de diezmos de la iglesia del lugar. Por lo demás, aquí percibe la mesa prioral 30 maravedís en 1338 que pueden constituir la renta señorial (humadga) en dinero consignada en el Becerro de las Behetrías -MarTínez Díez, Libro Becerro, I, pp. 309-310-, una obligación que se ha ańadido a la de hacer sernas, la única recogida en el Inventario de 1213.

59 Martínez Díez, Libro Becerro, I, pp. 327-328. En 1338 el monasterio ingresa 20 maravedís de martiniega y tres más en concepto innominado, mientras que en 1352 recibe 18 maravedís en concepto de yantar.

60 Estepa Díez, «Propiedad y señorío», p. 419, indica, a título de hipótesis, que es «la propiedad dominical el elemento más importante de la renta feudal de los dominios monásticos»; esto puede verse en los casos de Castroceniza, Huerta del Rey y Briongos, pertenecientes al dominio de Silos (García GonzÁLEZ, Vida económica, pp. 195-196). También es el caso de las heredades inmediatas al monasterio de San Zoilo, cuya cesión en 1338 procura unos ingresos muy superiores a los de los diezmos, resultando además que los molinos, huertos y casas de ese entorno procuran importantes ingresos al instituto. Pero entre los recursos empeñados del monasterio de San Zoilo vemos que se encuentran las heredades de Frómista, Villafrechós y Aguilar de Campos, que, tratándose de lugares en los que los monjes tienen sustanciosos y antiguos derechos decimales, son los que más renta potencial devengarían al monasterio de no estar en dicha situación y que esta renta se vincula en la fuente de modo explícito en Frómista y Aguilar a centros eclesiásticos. En Frómista y Villafrechós explotaban sus heredades en 1213 mediante ocho y tres yugos, respectivamente, pudiendo obtener 120-160 cargas en el primer caso y 45-60 en el segundo, mientras que las Cuentas indican que la renta de Frómista vale 400 cargas de pan y 200 la de Villafrechós. El monasterio dispone en Aguilar de cuatro yugos en 1213, pero obtiene 300 cargas en 1338. Es verdad que solo la extensión de la heredad de Villafrechós está 
resto de sus homólogos encuestados en las Cuentas de 1338, es decir, aunque con algunas excepciones $^{61}$, a la cesión a renta de sus heredades.

Otra cuestión es la que se refiere al viñedo monástico. En 1213 los monjes disponían de una importante dotación de vińas, aunque seguramente no las explotaban en su totalidad. En 1338, los autores que han estudiado las Cuentas perciben un generalizado interés de las comunidades por conservar bajo su control directo las viñas ${ }^{62}$. Por lo que respecta al monasterio carrionés, se imponen algunas matizaciones relevantes derivadas de la circunstancia de que la situación del viñedo parece haber experimentado desde 1213 -como sucede con el terrazgo cerealístico- una importante mutación que ha determinado que este recurso ya no sea gestionado directamente por los monjes; incluso podemos pensar que a veces ha sido abandonado o sustituido por otro cultivo, lo cual podría suponer, en su caso, un incremento de la propiedad dominical dedicada al cereal. Si los monjes dejan de percibir una parte sustancial de la producción vitícola por hallarse empeñada -2.200 cántaras-, se ha dado por hecho que la que viene «en salvo» -1.080 cántaras- sería imputable a la explotación directa ${ }^{63}$. Tratemos en primer lugar del vino que viene "en salvo» al monasterio. No se consigna ninguna partida de gasto para el cuidado y explotación de los viñedos en las cuentas del monasterio, a diferencia de lo que ocurre en los demás institutos, que realizaban importantes desembolsos para la realización de las labores aplicadas a estos cultivos ${ }^{64}$. San Zoilo cuenta, bajo la autoridad directa del prior, con un equipo humano consistente en "10 omes e cinco rapazes» -y que se podrían ampliar acaso con el concurso de alguno de los «30 omes racioneros» que reciben pan y vino del prior- que son beneficiarios de soldadas en dinero y productos. Cabe suponer que, al menos, se ocuparían de la "viña que ay al pie del monasterio", de la que se obtienen 80 cántaras. Pero en los otros lugares en los que se allega vino hasta redondear las 1.080 cántaras -Villamuera, Cardeñosa ${ }^{65}$, Villalumbroso, Añoza, San

evaluada con precisión en 1213, pero creemos que los datos merecen ser tenidos en cuenta, al menos a título indiciario. No habiendo realizado el monasterio en estos lugares, que sepamos, operaciones inmobiliarias después de 1213, cabe otorgar verosimilitud a lo dicho. Por otra parte, las cuentas del siglo xvI que estudiamos más adelante nos muestran que los derechos decimales -los de Frómista se perdieron en 1427- obtenidos en la parroquia del monasterio de San Zoilo, Villafrechós, Aguilar, Arconada, Villamuera y Villalumbroso -en estas dos últimas los monjes cobraban además infurciones en 1213, y en Arconada y Villamuera humazgas a mediados del siglo XIV- constituyen una parte muy relevante de sus ingresos en cereal. El del monasterio de San Esteban de Villamayor, donado por Fernando III en 1226 -Pérez Celada, Documentación I, doc. 88-, es un caso peculiar, ya que desde este momento desaparece de la documentación para resurgir a mediados del siglo XVI y, como puede verse en las contabilidades que glosamos en el último capítulo, ofrecer unas recaudaciones decimales que son las mayores del dominio, duplicando casi el monto de los arrendamientos de las tierras trigueras y acercándose al triple del obtenido en las parcelas de cebada arrendadas en el lugar.

${ }_{61}$ Estas son las de parte del terrazgo cerealístico de las abadías de Obarenes, Oña, Hornillos, Sahagún y, sobre todo, Santo Domingo de Silos. Solo el modesto cenobio de Obarenes explota todo su terrazgo de modo directo.

62 Moreta Velayos, Rentas monásticas, pp. 88-89.

63 Ibidem, p. 89.

64 García González, Vida económica, p. 78; Moreta Velayos, Rentas monásticas, p. 91.

65 Cardeñosa es el único lugar, junto con Carrión y Fuentes de Valdepero, del que se dice expresamente que alberga vińas propias del monasterio: «En las viñas de Cardeñosa [...] 150 cántaras» (Pérez Celada, Documentación II, doc. 215, p. 82). 
Mamés y Frómista-, resulta poco verosímil que estos criados monásticos pudieran aplicar su fuerza de trabajo al vińedo. Así, cabe pensar que los ingresos procedentes de estos núcleos tenían en general un carácter rentístico/tributario, ajeno a la explotación directa. En Villamuera, donde obtienen los monjes en 1338 la mayor partida de vino «en salvo» -400 cántaras-, podían exigir, según el Becerro de las Behetrías, sernas en 1352, aunque vinculadas al uso de bueyes. Sin embargo, el cenobio percibe diezmos en el lugar y lo seguirá haciendo después. En los restantes lugares no hay dotación de trabajo compulsivo, pero en todos ellos, salvo en Añoza, tienen también los monjes derechos decimales en iglesias $^{66}$, lo cual nos pone ante una procedencia de estos ingresos en vino diferente de la de la explotación directa. Por lo que se refiere al vino empeñado, supone 2.200 cántaras, y tampoco podemos afirmar que procediera de la explotación directa antes de su entrada en tal situación. En efecto, del vino empeñado en Frómista y Villafrechós -en las que también tienen derechos decimales los monjes-, que supondría en otras circunstancias 1.700 cántaras para el cenobio, se dice que procede de renta por valor de dicha cantidad, mientras que las viñas de Fuentes de Valdepero -donde no tienen diezmos los monjes«solían rentar» 500 cántaras $^{67}$. En fin, a tal punto es imprecisa esta contabilidad de San Zoilo, que solo recoge, por lo que se refiere a derechos decimales, percepciones explícitas en tres lugares: el monasterio de San Zoilo, Fuentes de Don Bermudo (Fuentes de Nava) y San Juan de Cestillos, cuando, en efecto, sus derechos eclesiásticos tenían una entidad mucho mayor ${ }^{68}$.

En lo que respecta a los ingresos de la comunidad en dinero, hay que señalar que las cesiones de huertos, molinos y casas en el entorno de Carrión devengan importantes cantidades a la comunidad ${ }^{69}$. Hay asimismo otras cesiones de la propiedad dominical que se cobran en dinero, como puede verse en el caso de la casa de San Pelayo de Toro ${ }^{70}$ - de la que habría que separar dos de sus dependencias, Pedrosa y Benafarces, que se hallan empeńadas, sucediendo que al menos en la segunda los monjes tenían derechos señoriales además de los dominicales-y en la de Villalpando. Por lo demás, en los únicos casos en que se mencionan en 1338 derechos señoriales/jurisdiccionales, estos remiten

66 Pérez Celada, El monasterio, p. 201.

67 Pérez Celada, Documentación II, pp. 85-86. En Frómista, la percepción de vino se asocia de modo expreso a la iglesia de San Martín ( 1 U500 cántaras de vino en la iglesia de San Martín»). La mayoría de las posesiones monásticas en Frómista -incluidos los diezmos- pasaron a manos de los señores de la villa en 1427 (Pérez Celada, Julio A. "Los conflictos jurisdiccionales en el barrio de San Martín de Frómista en los siglos XIV y XV». Cuadernos Burgaleses de Historia Medieval, 1995, vol. 3, pp. 178-179).

68 Pérez Celada, El monasterio, pp. 202-203. Los lugares con iglesias en las que los monjes perciben diezmos a mediados del siglo Xvi -según la fuente que analizamos en el último capítulo- son: el barrio de San Zoles (Carrión), Arconada, Aguilar de Campos, Villafrechós, Villalumbroso, Villamayor de Campos, Villamuera y Villalpando, resultando que los ingresos de este producto no atribuibles a la explotación directa provienen de los diezmos de Villamuera y Villafrechós.

69 Pérez Celada, El monasterio, pp. 140-174 y 287-313, donde podemos ver que constituyeron históricamente recursos relevantes que, en el caso de huertos y molinos, fueron objeto parcial de explotación directa.

70 El monasterio perdió el control de la casa de Toro y sus dependencias en el siglo xv: PÉrez CELADA, Julio A. «La 'casa' de San Pelayo de Toro y sus dependencias entre los siglos XI y XV». En Actas del I Congreso de Historia de Zamora. Zamora, 1988, vol. III, pp. 223-231. 
al cobro en dinero de martiniegas y tienen como objeto, salvo en un caso, villas situadas bajo el dominio exclusivo de los monjes ${ }^{71}$.

Las rentas monásticas provienen, pues, tanto de la cesión de la propiedad dominical como -y ello de un modo con frecuencia implícito en la fuente- del ejercicio del dominio señorial ${ }^{72}$ y del de la jurisdicción eclesiástica. En pocas ocasiones consta de modo explícito que la cesión de la propiedad dominical es la fuente de renta exclusiva o principal ${ }^{73}$. Los autores de las cuentas de San Zoilo, insistamos, no ponen cuidado en general en discernir el origen preciso de las rentas, ni en el caso del cereal, ni en el del vino, ni en el de la moneda.

En fin, el monasterio, al igual que sus homólogos recogidos en las cuentas, tiene una parte muy importante de su patrimonio en situación de «empeńo». Hay bienes que están en manos de su beneficiario "por fuerza», lo que nos pone ante una inseguridad ambiental nada episódica, y otros por los que no se ha percibido nada, aunque no medie fuerza en su deposición, circunstancia que puede guardar concomitancias con la figura del prestimonio de siglos anteriores, que no solía conllevar, al menos formalmente, un reconocimiento oneroso ${ }^{74}$. Pero varios empeños se vinculan a una contraprestación económica y revelan las dificultades por las que está atravesando la institución. Esta, en efecto, se halla endeudada y con graves dificultades para percibir ingresos de sus propiedades y dependientes, como ya se ponía de manifiesto en $1325^{75}$. En estos empeños, el concesionario hace un pago por adelantado a cambio del disfrute de unos bienes cuya renta, al finalizar el período de deposición de su dominio por los monjes, supera ampliamente el valor de lo entregado por aquel en las cuatro ocasiones en que se producen dichos empeños. Estos no constituyen sino la devolución de un préstamo hecho a la comunidad cuyos intereses serían, grosso modo, la diferencia entre lo entregado por el concesionario al principio del disfrute del bien -esto es: el principal- y la suma de todas las rentas devengadas por el mismo durante el tiempo que dura el mencionado disfrute. Los omes de Villalón, Mari Fernández,

71 Calzada de los Molinos no es señorío exclusivo de los monjes. Arconada, por su parte, aparece en el Becerro de las Behetrías como un señorío compartido por San Zoilo y San Román de Peñas, también cluniacense. El resto son Villamuera, el barrio de San Zoles y Villaverde de Volpejera.

72 Aparte de los casos ya mencionados de Arconada y Villamuera, los de Villaires, Villarmienzo, Revilla, Valcabado, Lobera o Gañinas nos ponen ante la percepción de renta señorial por los monjes que no consta explícitamente en 1338 (Martínez DíEz, Libro Becerro, vol. II, pp. 62, 43, 87, 55, 58 y 62, respectivamente).

73 Este es el caso del «pie del monasterio» de San Zoilo, cedido «a quinto e quarto de pan» -aquí, además, la cesión de molinos, huertos y casas devenga ingresos en moneda muy importantes-; el de Villaverde de Volpejera, cedido a tercias - no consta en 1338 que el monasterio tiene derechos señoriales en el lugar, pagaderos en moneda, según revelará el Becerro de las Behetrías-; los de Bárcena y «del convento» (sic), adscritos a la Sacristanía, que lo están a medias; el de Fuentes de Valdepero, que ya se arrendaba en 1213 y del que, hallándose empeñado ahora, consta que sus heredamientos rentaban 60 cargas de pan (Pérez CELADA, Documentación II, pp. 81, 86 y 87); y los de la cassa de Toro y la cassa de Villalpando, cedidos por 3.000 y 2.000 maravedís, respectivamente.

74 Martínez Sopena, La Tierra de Campos, p. 268. Por lo demás, los empeños tienden a confundirse con la figura de las «encomiendas monásticas»: Estepa DíEz, «Propiedad y seńorío», p. 401.

75 Pérez Celada, Documentación II, doc. 193. 
JULIO A. PÉREZ CELADA

LA EXPLOTACIÓN DIRECTA DE LA PROPIEDAD DOMINICAL MONÁSTICA

EN LA CUENCA DEL DUERO. LOS CLUNIACENSES

Fernando García Duque o los hijos de Jimeno Díaz no son, pues, sino prestamistas del monasterio ${ }^{76}$.

Al margen de los empeños, una circunstancia pasajera, nos hallamos ante una situación de deposición generalizada de los bienes inmuebles monásticos que afecta, además de a las heredades y a las vińas, a bienes como los huertos y los molinos, y que va a ser ya la tónica dominante en los siglos posteriores hasta la Desamortización. Hasta mediados del siglo XVI no se producirá una parcial y deliberada recomposición de la explotación directa, si bien nos consta la continuidad de la misma desde tiempos medievales en los mencionados lugares de Arconada y Villamuera -en los que dicha explotación se realizaba mediante trabajo compulsivo-, una continuidad que se prolongará hasta 1558 en el primer caso y hasta mediados del siglo xVII en el segundo. Por lo demás, no cabe descartar del todo la existencia de explotación directa, por ejemplo, en el entorno del monasterio en el siglo $\mathrm{Xv}^{77}$. En fin, la gestión global del patrimonio en tiempos bajomedievales y en la primera mitad del siglo Xvi ya fue tratada por nosotros -en la medida de lo posible- en su día ${ }^{78}$.

76 Pérez Celada, Documentación II, doc. 215. Las cuentas de los demás monasterios recogen múltiples ejemplos, algunos tan explícitos como estos: Juan Pérez de Berzosa percibe la renta de varios lugares de San Salvador de Oña "por dineros que prestó al monasterio», y la casa de la Estrella y un molino del monasterio de Silos los «tiene Juan Pérez [...] por 3.000 maravedís que nos prestó [...]; quando le diéremos los dineros, que nos dexe nuestra casa» (García González, Vida económica, pp. 148 y 204). Sobre la distinción, meramente formal, entre la renta adelantada y el préstamo explícito en las Cuentas, Clavero, Bartolomé. Mayorazgo, propiedad feudal en Castilla (1369-1836). Madrid: Siglo XXI, 1974, p. 428.

77 Como ya hemos indicado, a mediados del siglo xv el monasterio exige en Villamuera, junto a la entrega de dos cántaras de mosto, 20 peones anuales para la siega u otras labores (Pérez CeLADA, El monasterio, pp. 342 y 216, respectivamente); en 1553, además de recibir las mencionadas medidas de mosto de cada vecino "que coxe de çinquenta cántaras de vino e dende arriba", se beneficia aún de "veinte obreros para segar sus panes el monesterio» (Alonso Martín, M. a Luz y PAlacio SÁnChez-IzQUierdo, M. ${ }^{a}$ Luisa. Jurisdicción, gobierno y hacienda en el señorio de abadengo castellano en el siglo XVI. Madrid: Editorial Complutense, 1993, p. 102), una circunstancia que perdurará hasta el siglo Xvir. Los campesinos de Arconada, por su parte, realizaron sernas hasta 1558, cuando las redimieron pagando 178.125 maravedís (Alonso Martín y Palacio Sánchez-Izquierdo, Jurisdicción, gobierno y hacienda, p. 43, n. 77). En fin, por poner un ejemplo de lo expresado en relación con la posible existencia de otras explotaciones directas en el siglo xv, el apeo de un conjunto de parcelas cercanas al monasterio de San Zoilo realizado el 10-VIII-1481 nos presenta, entre otras cosas, 26 tierras arrendadas que suman 51 obradas y una huerta cedida a fuero, pero también 16 tierras (22 obradas) y 22 huertos (29,5 obradas) de cuyo régimen de explotación nada se dice.

78 Pérez Celada, El monasterio, capítulos V y VII, especialmente. Podría tener interés a priori establecer una comparación entre la extensión aproximada del terrazgo en 1213 y la que nos muestran los apeos de propiedades que menudean en los siglos xv y xvi. Lo cierto es que un intento en tal sentido resulta decepcionante. Desde la idea de que la extensión del terrazgo monástico no experimentó variaciones sustanciales entre el siglo XIII y el XVI, hicimos una comparación de las superficies de las tierras cerealísticas en 1213 con las que consignan los apeos. Teniendo en cuenta que no todos los lugares son apeados y que a menudo los apeos se refieren solamente a algunas de las tierras monásticas en un determinado lugar, los únicos núcleos en que hay una continuidad meramente aproximativa de la extensión de las heredades entre 1213 y los siglos XV y XVI, serían Bahíllo, que contaba con 2 yugadas en 1213 y con cerca de 50 obradas en 1481 y 1516 (PÉrez Celada, El monasterio, pp. 343 y 348); Castrillo de Macintos, que tenía una yugada en 1213 y unas 30 obradas en 1464 (ibidem, p. 334) y 22,5 en 1512 (ibidem, p. 340); San Mamés, que albergaba una yugada en 1213 y 60 obradas en 1481 (ibidem, p. 343); y Villaturde, con dos yugadas en 1213 y 88,5 obradas en 1516 (ibidem, p. 347). 
JULIO A. PÉREZ CELADA

LA EXPLOTACIÓN DIRECTA DE LA PROPIEDAD DOMINICAL MONÁSTICA

EN LA CUENCA DEL DUERO. LOS CLUNIACENSES

A lo largo de este siglo, las cesiones de bienes monásticos van a ir amoldándose a diversas modalidades preferentes: arrendamientos a corto plazo pagaderos en especie para las tierras de cereal y deposiciones más prolongadas para los demás bienes -vińas, huertos- por las que se suelen exigir rentas en dinero. Junto a estas cesiones, las devaluadas rentas feudales «antiguas» en numerario o en especie, los ingresos monetarios de diversa procedencia y las percepciones decimales - muy importantes en la economía monásticacompletan, junto con la explotación directa, las partidas de ingresos del instituto ${ }^{79}$.

La explotación directa va a experimentar una revitalización selectiva que se plasmará en la configuración de dos núcleos en el dominio sometidos a tal régimen y cuya situación perdurará secularmente: los alrededores del monasterio, en los que una parte del terrazgo se explotará directamente mientras que otra sigue sometida a un régimen de cesión a terrazgueros, y la granja de Villaverde de Volpejera ${ }^{80}$, un lugar en el que, al igual que en las inmediatas Villamuera y Cardeñosa de Volpejera, los monjes habían ostentado históricamente el señorío exclusivo. En los tres núcleos desarrollaron los monjes importantes explotaciones directas, como se desprende de que en 1213 fueran beneficiarios de sernas campesinas y poseyeran yugos de bueyes y domos en todos ellos. Lo cierto es que la presencia del monasterio en Cardeńosa se eclipsa en el siglo Xv, mientras que en Villamuera y Villaverde la institución estará asentada hasta la Desamortización. Villaverde se despobló en algún tiempo posterior a 1352, y en el siglo xv y la primera mitad del XVI sus tierras fueron objeto de cesiones a los concejos de Paredes de Nava y Villamuera para su aprovechamiento ganadero ${ }^{81}$; a mediados de la décimosexta centuria, los monjes decidirán su conversión en granja, configurando en ella una importante explotación agropecuaria ${ }^{82}$.

79 En relación con las modalidades de cesión, Yun Casalilla, Bartolomé. Sobre la transición al capitalismo en Castilla. Economía y sociedad en Tierra de Campos (1500-1830). Valladolid: Junta de Castilla y León, 1987, pp. 170-182; y Pérez Celada, El monasterio, pp. 301-333.

80 A estos dos enclaves debe sumarse Villamuera: según hemos dicho, los monjes podían exigir desde 1451 dos cántaras de mosto y 20 peones anuales para la siega u otras labores como conmutación de sernas preexistentes; ahí obtenían vino en 1560, 1561 y 1562 procedente de sernas en cantidad no especificada, aunque dichas sernas pudieran no ser otra cosa que las cántaras de mosto que entregaban los dependientes a los monjes desde dicho año de 1451 y todavía lo seguían haciendo en 1553 (ver n. 76). En este momento, queda claro que los 20 peones u obreros que exigen los monjes al colectivo campesino se aplican a la siega del cereal, pero en la fuente contable que analizaremos a continuación no hay imputación alguna de ingresos en cereal procedentes de la explotación directa en Villamuera. Por lo demás, no está nada claro cómo se realizaban las labores previas a la siega, porque no nos consta la existencia de animales de labor en dicho lugar a mediados del siglo xvi, aunque sí en la cercana Villaverde de Volpejera, cuando menos desde 1561 .

81 Martín Cea, Juan Carlos. El mundo rural castellano a fines de la Edad Media. El ejemplo de Paredes de Nava en el siglo XV. Valladolid: Junta de Castilla y León, 1991, pp. 85-86 y 107. Villaverde, según nos muestra el Becerro de las Behetrías, se hallaba poblada en el momento de su realización (MarTínez Díez, Libro Becerro, t. I, p. 329).

82 En las granjas de la comarca burgalesa en el siglo xv, Casado Alonso, Señores, mercaderes y campesinos, pp. 72-84, observa que "no hay una predominante dedicación ganadera" (ibidem, p. 82), a diferencia de lo que sucede en Villaverde de Volpejera en el siglo Xvi. 
JULIO A. PÉREZ CELADA

LA EXPLOTACIÓN DIRECTA DE LA PROPIEDAD DOMINICAL MONÁSTICA

EN LA CUENCA DEL DUERO. LOS CLUNIACENSES

En los años 1560, 1561 y 1562 se realizan unas detalladas contabilidades referidas al dominio de San Zoilo que nos permiten conocer, entre otras cosas, la entidad y el régimen de aprovechamiento de la explotación directa en dichos años ${ }^{83}$. Así, en 1560, la granjería o coxeta -es decir, la explotación directa- procura a los monjes 95 cargas de trigo, 125 de cebada, 220 cántaras de vino ${ }^{84}, 130$ corderos y 320 vellones; en 1561, 53 cargas de trigo, 102 cargas de cebada, 250 cántaras de vino, 200 corderos, 400 vellones y 40 quesos; en fin, en 1562 los monjes obtienen 106 cargas de trigo, 136 de cebada ${ }^{85}, 250$ cántaras de vino, 230 corderos, 600 vellones y 80 quesos.

Hay que notar el carácter diferenciado de ambos enclaves, Carrión y Villaverde de Volpejera. El primero tiene una dedicación agrícola convencional, es decir, procura trigo, cebada y vino, mientras que el segundo muestra una acusada dedicación pecuaria y alberga el rebańo de ovejas que produce los corderos, los vellones y los quesos reseñados más arriba. Precisamente, en Villaverde los monjes realizan obras en la casa en 1561 y 1562 al objeto de acondicionarla como centro agrícola complementario del ganadero ${ }^{86}$ y rendirá la modesta cantidad de 11 cargas de trigo y acaso algunas más de cebada en este último año, sin que tengamos noticia expresa de que obtuvieran en ella cereal en los años inmediatamente anteriores ${ }^{87}$. La cabaña ovina del monasterio tiene un carácter estante y una entidad modesta, si se compara con la que se halla en manos de otras entidades señoriales ${ }^{88}$, y se comienza a configurar en los términos que presentan las cuentas precisamente tras la conversión de Villaverde en granja, ya que antes nunca se había documentado ${ }^{89}$. Desde este momento, los monjes explotarán su rebaño ovino de un modo planificado, haciéndolo pastar en los espacios inmediatos a la granja. En la cercana Villamuera el monasterio posee prados -calificados de pratis bonis en 1213- que tiene arrendados por 3.375 maravedís anuales ${ }^{90}$.

83 AHN. Clero. Legajo 5330, Relaçión y quenta de la renta en dinero y pan del monesterio de Sant Zoyl de Carrión de los tres años de sesenta, sesenta e vno y sesenta y dos, y quenta del gasto y reçibo en dinero de todos los tres años. Hecha a doçe de marzo de 1563 años de comisión de Nro. M. R. P. por frai Xhristóual de Agüero [en adelante, Relaçión]. En Pérez Celada, El monasterio, pp. 311-325, un estudio general de la fuente.

84 La Relaçión nos habla de «las vinnas de casa» (fol. 3v), por lo que entendemos que el viñedo monástico está en Carrión.

85 Ibídem, fols. 1v-5. La contabilidad por partida doble -diferenciada de los resúmenes de ingresos que la Relaçión recoge en los mencionados folios- ofrece en el año 1562 cifras distintas: 77 cargas de trigo y 118 de cebada. (ibidem, fols. 11v y 14v).

86 Ibidem, fols. 8 y 9 .

87 Ibidem, fol. 11v.

88 En 1563 el monasterio dispone de «doçientos y çinquenta carneros y ochenta borros, además de treçientas y setenta obeias y borras» (ibidem, fol. 20). Sobre la tardía dedicación a la ganadería de estos monjes, PÉrez Celada, El monasterio, pp. 143-151.

89 El monasterio percibe, en los años de confección de las cuentas, 34.000 maravedís anuales por el erbaxe del Puerto del Ves, un pastizal en la Montaña palentina que perteneció a San Román de Peñas hasta su anexión a San Zoilo en el siglo xv (Relaçión, fols. 1v-3v). Ninguno de los dos cenobios lo utilizó jamás para sus rebaños: Pérez Celada, Julio A. «El monasterio de San Román de Entrepeñas en la Edad Media». En Actas del III Congreso de Historia de Palencia. Palencia: Diputación Provincial, 1995, vol. II, pp. 475-482.

90 Relaçión, fols. $1 \mathrm{v}-3 \mathrm{v}$. Sobre la explotación planificada de su cabaña por los monjes da idea el hecho de que entre 1559 y 1563 se han "conprado casi quinientas cabeças de ganado ovexuno" (Relaçión, fol. 19v). Sabemos además que a fines del ejercicio de 1559 el monasterio sólo contaba con 200 ovejas (ibidem, 
JULIO A. PÉREZ CELADA

LA EXPLOTACIÓN DIRECTA DE LA PROPIEDAD DOMINICAL MONÁSTICA

EN LA CUENCA DEL DUERO. LOS CLUNIACENSES

Por lo que se refiere al equipamiento animal dedicado a las labores agrícolas en estas dos explotaciones directas, los monjes poseen en 1563 -es en este año cuando se inventarían los animales- dos pares de mulas de labranza dedicadas al trabajo en las tierras cercanas al monasterio, una circunstancia que se aviene con la amplia presencia que tiene ahora el recurso a estos animales en el campo castellano y con lo adecuados que resultan para labrar un conjunto de heredades que se hallan muy dispersas, como corresponde al acusado minifundismo del paisaje agrario castellano en general y del patrimonio monástico en particular, según muestran los apeos de sus tierras; la granja de Villaverde, en cambio, con un terrazgo cerealístico y pastizales de uso exclusivo del monasterio, alberga dos parejas de bueyes destinadas al trabajo en la heredad monástica en 1563, constándonos que se ha comenzado a sembrar trigo y cebada en ella en $1561^{91}$.

Es de interés el capítulo de los gastos que precisa el sostenimiento de las explotaciones directas de la institución. Existe personal aplicado de modo permanente a las mismas y sostenido a expensas del monasterio. Así, en Carrión se hallan «dos moços que andan con las mulas de labrança», tres hortelanos ${ }^{92} \mathrm{y}$ "vn hombre que anda sobre la granxa», es decir, un guarda; a ellos se suman otros servidores y empleados sin dedicación expresa a la explotación directa, aunque algunos acaso se ocupen, por ejemplo, del viñedo. En Villaverde nos encontramos con dos mozos «que andan con dos pares de bueyes», un pastor que es alimentado en la propia granja y otros tres que reciben salario en pan y dinero, un guarda, un caballerizo -encargado de cinco yeguas y dos muletas que allí poseen los monjes- y tres criadas $^{93}$. Los individuos aquí enumerados, junto a otros que tienen una vinculación laboral más o menos permanente con la institución, reciben salarios y soldadas en dinero, vino, trigo y cebada ${ }^{94}$, sin que consten por separado las entregas al personal aplicado a las explotaciones directas. El monasterio es, por lo demás, ampliamente autosuficiente en trigo y cebada, pero no en vino, cuya adquisición es objeto de importantes desembolsos, pese a que obtiene ingresos del mismo en concepto de diezmos y coxeta, e incluso, en el caso de Villamuera, de sernas ${ }^{95}$. La dedicación laboral de los sirvientes monásticos se ve complementada por el recurso a mano de obra eventual,

fol. 6). Las ovejas parieron 135 corderos en 1560, 200 en 1561 y 230 en 1562, y los corderos recibidos en concepto de diezmos fueron 25 en 1560, 30 en 1561 y 43 en 1562 (ibidem, fols. 2-4v). Hay que significar que a mediados del siglo xviII solo «ai ganado lanar a temporadas» en Villaverde -que, por lo demás, ha diversificado sus cultivos-, mientras que la inmediata Villamuera -donde posee importantes prados el monasterio desde la Edad Media- alberga 600 cabezas del cenobio (Archivo General de Simancas. Catastro de Ensenada. Respuestas Generales, Libro 628, fol. 736, y Libro 627, fol. 322v, respectivamente), lo que nos hace pensar que el monasterio combinaba de algún modo el uso de los pastos de ambos lugares.

${ }_{91}$ Relaçión, fol. 4v. Sobre la «cuestión» de las mulas y los bueyes, Anes, Gonzalo. «La 'Depresión' agraria durante el siglo xvir en Castilla». En Homenaje a Julio Caro Baroja. Madrid: Centro de Investigaciones Sociológicas, 1978, pp. 86-87; Casado Alonso, Señores, mercaderes y campesinos, pp. 177-178; y Brumont, Francis. Campo y campesinos de Castilla la Vieja en tiempos de Felipe II. Madrid: Siglo XXI, 1984, p. 117.

92 En 1240 los monjes contaban, entre sus excusados de pechos en el barrio de San Zoles, con un ortolano, dedicado, como estos tres de ahora, al trabajo en una parte de los muchos huertos que en la vega del Carrión tenía el monasterio (Pérez Celada, Documentación I, doc. 101).

93 Relaçión, fol. 17.

94 Ibidem, fols. 7-15.

${ }_{95}$ Ibidem, fol. 15v. Sobre el vino procedente de sernas en Villamuera, fols. 2-4. 
asalariada: en los tres años encontramos relevantes gastos dinerarios «en labrança» que, al menos en parte, han de vincularse a esta circunstancia ${ }^{96}$.

Por otra parte, encontramos los gastos en simiente que se realizan en los tres años, y que son de 18 cargas de trigo y 14,25 de cebada en 1560; de 21,5 y 24,75 en 1561; y de 17 y 20,5 en $1562^{97}$. Estas cifras nos pueden orientar sobre el tamaño de las heredades cerealísticas de la explotación directa en Carrión y Villaverde. Si nos atenemos a las cantidades consignadas en 1562, dichas heredades podían tener este año unas 30 cargas de sembradura, considerando que se suele usar más simiente de la indicada "teóricamente» ${ }^{98}$ para paliar contingencias como la esterilidad de parte de la misma. Si convertimos las 30 cargas de sembradura en fanegas, atribuyendo a la fanega de sembradura una equivalencia hipotética de 0,5 ha, obtenemos unas 60 ha de extensión aproximada de las heredades labradas, unas heredades que eran explotadas mediante el sistema de ańo y vez, por lo que nos encontramos con una extensión total de unas 120 ha o 240 obradas. Las dos parejas de mulas y las dos de bueyes que se documentan en 1563 confieren cierta verosimilitud al cálculo, pues, como sabemos, la yugada medieval ocupaba unas 25 ha $^{99}$. En cualquier caso, el monasterio no tenía por qué explotar siempre las mismas tierras, lo que puede explicar las variaciones interanuales en el gasto de simiente, y además todo indica que no comienza a trabajar las tierras de cereal en Villaverde hasta 1561, y ello de modo más bien modesto ${ }^{100}$. A mediados del siglo XVIII los monjes labran 162 obradas de cereal en este lugar - de las que obtienen trigo, centeno y cebada con tres parejas de bueyes- y 40 de viñas, mostrando que han ampliado y diversificado la explotación desde el siglo Xvi ${ }^{101}$. En fin, en la tercera década del siglo XIX, la comunidad explota en Carrión 91 obradas, con animales cuyo número ignoramos, y 168 en la granja de Villaverde, con cuatro pares de bestias ${ }^{102}$.

Otros gastos relevantes son los referidos al mantenimiento o mejora de los equipamientos productivos. Así, se realizan desembolsos en los tres ańos «en herraxe y aparexos de bestias». Además, hay partidas de cebada para «las mulas de labrança y cavalgaduras de cassa y

96 Ibidem, fols. 7-9.

97 Ibidem, fols. 10-15. Los gastos en simiente, comparados con las cosechas obtenidas el año siguiente a su realización, nos orientan sobre los rendimientos cerealísticos: 1:2,9 para el trigo y 1:7,1 para la cebada en 1561. En 1562, si consideramos las cifras ofrecidas por los resúmenes de ingresos o por las contabilidades por partida doble, que son algo distintas en este ańo, tendríamos 1:4,9-1:3,5 para el trigo y 1:5,5-1:4,7 para la cebada.

98 Clemente Ramos, La economía campesina, pp. 106-107.

99 Ignoramos los animales disponibles entre 1560 y 1562, aunque su número no debía de diferir mucho del de 1563. La yugada medieval no coincide con la vigente en Castilla en estos tiempos, en los que tal medida viene a coincidir con la obrada, es decir, una media ha (BRumont, Campo y campesinos, p. 31; y López García, La transición, p. 81); aunque también en la Edad Media hay yugadas de aproximadamente esta extensión (Clemente Ramos, La economía campesina, p. 105).

100 En 1562 los únicos ingresos en cereal explícitamente obtenido en Villaverde son 11 cargas de trigo -mientras que «la coxeta de cassa» (Carrión) es de 66- y quizá una cantidad parecida de cebada.

101 AGS. CE. RG. Libro 628. fols. 734-735v.

102 Francia Lorenzo, Santiago. «El monasterio de san Zoilo al tiempo de la Desamortización». En Notas de archivo (Anecdotario para la pequeña historia de un pueblo). Palencia: Diputación, 1985, pp. 36-37. El autor menciona en Villaverde en este momento una modesta presencia de ovejas y vińas. 
huéspedes» ${ }^{103}$, mientras que el sustento de los bueyes de Villaverde no halla una consignación explícita. En fin, ya lo hemos indicado, se realizan en 1561 y 1562 obras para acondicionar la granja de este núcleo como explotación agro-pastoril ${ }^{104}$.

También hay que referirse a las compras de dos productos. En primer lugar, el vino. La «empresa» carrionesa era ampliamente excedentaria en cereales, y los monjes almacenaban grandes cantidades de trigo y cebada con vistas a la especulación ${ }^{105}$; sin embargo, era muy deficitaria en vino, ya que, habiendo cedido a cambio de cánones en dinero la inmensa mayoría de sus vińas, solo ingresaba este producto, ya lo hemos seńalado, en concepto de diezmos y de explotación directa en el entorno de Carrión y, mediante sernas, en Villamuera ${ }^{106}$. Así, obtuvo 1.120 cántaras de diezmos y 220 de la explotación directa en $1560,1.250$ y 250 en 1561 y 1.450 y 250 en 1562 . El «mayordomo y çelleriço», por su parte, estiman que el consumo total de vino en los tres años supone 5.475 cántaras, lo que, para cubrir la diferencia con lo ingresado, ha supuesto un desembolso de 75.756 maravedís ${ }^{107}$. Otro producto de interés es la leńa. Dijimos que en 1213 los monjes se hacían traer, mediante labores de recogida y acarreo, la leña de sus posesiones del norte del dominio, mientras que en 1338 -no constando tal ingreso- la compra de esta suponía un gasto para la mesa prioral de 7.620 maravedís ${ }^{108}$. En el siglo Xvi continúan las compras, y la institución dedica a leña y carbón 14.996 maravedís en 1560, 3.434 en 1561 y 5.069 en 1362; sin embargo, todos los ańos ingresa 30 carros de leńa en concepto de renta, suponemos que procedentes del norte del dominio, como en $1213^{109}$.

Para concluir, conviene evaluar el peso de la explotación directa en la economía del dominio. En 1560 esta aporta el 12,3\% del trigo, el 19,2\% de la cebada y el 19,6\% del vino; en 1561, el 9,1\% del trigo, el $25 \%$ de la cebada y el $20 \%$ del vino; en fin, en 1562 , el $11,5 \%$ del trigo, el $19,4 \%$ de la cebada y el $17,2 \%$ del vino ${ }^{110}$. Hay que decir,

103 Relaçión, fols. 7, 8, 9, 13, 14 y 15.

104 Ibidem, fols. 8 y 9.

105 Pérez Celada, El monasterio, p. 323.

106 Relaçión, fols. 2-4. Recordemos que en 1451 se pacta con los vecinos de Villamuera que las «huebras y sernas» que hacían queden conmutadas por dos cántaras de mosto por cabeza y 20 peones anuales que estarán vigentes hasta 1646, en que se redimen por 500 maravedís. A mediados del siglo xviII paga el lugar al monasterio 30 reales de vellón "por rrazón de peones, lámparas y altar, además de doscientos veinte y un reales que se gastan en vino para las sernas que se hazen» (AGS. CE. RG. Libro, 627, fols. 326v-327). Un ejemplo de pervivencia de prestaciones personales hasta mediados del siglo XVIII, en el priorato cisterciense de Perales, cercano a Villamuera, donde los campesinos debían hacer 12 sernas al año (GARcía SANZ, Ángel. «Cultivo, rendimientos y coyuntura agraria en tierras de Palencia en el Antiguo Régimen: la explotación del priorato de Perales, 1719-1829». En Actas del II Congreso de Historia de Palencia. Palencia: Diputación Provincial, 1990, vol. IV, p. 13); también, para el primer tercio del siglo xIx en el dominio de Sahagún, García Martín, Pedro. El monasterio de San Benito de Sahagún en la Edad Moderna. Valladolid: Junta de Castilla y León, 1985, pp. 178-179.

107 Relaçión, fol. 16.

108 Pérez Celada, Documentación II, p. 85.

109 Relaçión, fols. 2, 3, 4v, 7, 8 y 9.

110 Los ingresos de trigo y cebada en 1562 no son iguales en los resúmenes de ingresos (ibidem, fol. $4 \mathrm{v})$, sobre los que hemos hecho el cálculo, y en la posterior contabilidad por partida doble: ahí la coxeta fue de 77 cargas de trigo y 118 de cebada, lo que supondría que la aportación de la explotación directa se reduciría al $8,3 \%$ y $16,8 \%$, respectivamente (ibidem, fols. $11 \mathrm{v}$ y $14 \mathrm{v}$ ). 
en cualquier caso, y para matizar el "peso" de los ingresos en especie, que los recibidos directamente en dinero suponen en los tres ańos entre el $35,4 \%$ y el $40,7 \%$ del valor monetario total de lo que obtiene la institución.

El dominio de San Zoilo de Carrión es, pues, a estas alturas del siglo xvi una empresa agrícola excedentaria y saneada que, a diferencia de lo que ocurría en 1338, puede mantener con holgura a un colectivo de 17 monjes -a los que cabría sumar los tres que "anse muerto de pocos días acá» en 1563-, tres donados, 29 servidores, dos monjes con sus respectivos criados que se hallan en los prioratos y algunos clérigos parroquiales ${ }^{111}$. A ello coadyuva una explotación directa mucho menor que la de 1213 , pero que representa una parte nada desdeñable de los ingresos en especie de la institución.

TABLA 1.- La explotación directa en el Inventario de 1213.

\begin{tabular}{|l|c|c|c|c|c|c|c|c|}
\hline Lugares & A & B & C & D & E & F & G & H \\
\hline Aguilar de Campos* & & $\mathrm{X}$ & $\mathrm{X}$ & & & $\mathrm{X}$ & & \\
\hline Añoza* $^{*}$ & & & & & $\mathrm{X}$ & $\mathrm{X}$ & & \\
\hline Arconada I** & $\mathrm{X}$ & $\mathrm{X}$ & $\mathrm{X}$ & & & & & $\mathrm{X}$ \\
\hline Arconada II & & & & & $\mathrm{X}$ & $\mathrm{X}$ & & \\
\hline Autillo & & $\mathrm{X}$ & $\mathrm{X}$ & & & $\mathrm{X}$ & & \\
\hline Bahíllo & & & & $\mathrm{X}$ & & & & \\
\hline Becerril de Campos & $\mathrm{X}$ & & & $\mathrm{X}$ & & $\mathrm{X}$ & & \\
\hline Calzada de los Molinos & & & & & & & & $\mathrm{X}$ \\
\hline Calzadilla de la Cueza & & & & & & & & \\
\hline Cardeńosa de Volpejera & $\mathrm{X}$ & $\mathrm{X}$ & $\mathrm{X}$ & & & $\mathrm{X}$ & & $\mathrm{X}$ \\
\hline Castrillo de Macintos* & & & & $\mathrm{X}$ & & $\mathrm{X}$ & & \\
\hline Castrocisneros & & & & $\mathrm{X}$ & & & & \\
\hline Cestillos & & $\mathrm{X}$ & & $\mathrm{X}$ & & $\mathrm{X}$ & & \\
\hline Cisneros & & $\mathrm{X}$ & & $\mathrm{X}$ & & $\mathrm{X}$ & & \\
\hline Frechilla & $\mathrm{X}$ & & & $\mathrm{X}$ & & $\mathrm{X}$ & & \\
\hline Fuentes de Nava (Fuentes de Don Bermudo) & & $\mathrm{X}$ & & & & $\mathrm{X}$ & & \\
\hline Fuentes de Valdepero* & & & & $\mathrm{X}$ & & $\mathrm{X}$ & & \\
\hline Gañinas** & $\mathrm{X}$ & & $\mathrm{X}$ & & & & & $\mathrm{X}$ \\
\hline
\end{tabular}

111 Ibidem, fols. 16v-17. También, Pérez Celada, Documentación II, doc. 215. A mediados del siglo XVIII el monasterio «mantiene dentro de la clausura treinta y quatro monges y fuera de ella en administraciones y colegios veinte y nueue» (AGS. CE. RG. Libro 629, fol. 223v). 
JULIO A. PÉREZ CELADA

LA EXPLOTACIÓN DIRECTA DE LA PROPIEDAD DOMINICAL MONÁSTICA

EN LA CUENCA DEL DUERO. LOS CLUNIACENSES

\begin{tabular}{|c|c|c|c|c|c|c|c|c|}
\hline LUGARES & $\mathbf{A}$ & B & C & D & $\mathbf{E}$ & $\mathbf{F}$ & G & $\mathbf{H}$ \\
\hline Lobera* & & & & & $\mathrm{X}$ & & & $\mathrm{X}$ \\
\hline Mayorga & & $\mathrm{X}$ & & & & $\mathrm{X}$ & & \\
\hline Mazuecos de Valdeginate* & & & & & $\mathrm{X}$ & & & \\
\hline Paredes de Nava & $\mathrm{X}$ & & & $\mathrm{X}$ & & $\mathrm{X}$ & & \\
\hline Pozuelos de Amianos & & & & & $\mathrm{X}$ & & & \\
\hline Revenga & & & & & $\mathrm{X}$ & & & $\mathrm{X}$ \\
\hline Riberos de la Cueza & & & & & & $\mathrm{X}$ & & \\
\hline Riosmenudos & & $\mathrm{X}$ & & $\mathrm{X}$ & & & & \\
\hline Robladillo & & & & $\mathrm{X}$ & & & & \\
\hline San Andrés de Congosto* & $\mathrm{X}$ & $\mathrm{X}$ & $\mathrm{X}$ & & & & $\mathrm{X}$ & \\
\hline San Felices & & $\mathrm{X}$ & & $\mathrm{X}$ & & $\mathrm{X}$ & & \\
\hline San Mamés I & & & & & $\mathrm{X}$ & $\mathrm{X}$ & & \\
\hline San Mamés II & & $\mathrm{X}$ & & $\mathrm{X}$ & & & & \\
\hline San Martín de Frómista & $\mathrm{X}$ & $\mathrm{X}$ & $\mathrm{X}$ & & & $\mathrm{X}$ & & \\
\hline San Martín de los Álamos & & & & $\mathrm{X}$ & & & & \\
\hline San Román (Tierra de) & & & & & & & & $\mathrm{X}$ \\
\hline \multicolumn{9}{|l|}{ San Sebastián de Liébana* } \\
\hline Santa Cruz de Cea* & & $\mathrm{X}$ & & & & & & \\
\hline San Zoilo de Carrión I & $\mathrm{X}$ & $\mathrm{X}$ & $\mathrm{X}$ & & & $\mathrm{X}$ & & \\
\hline San Zoilo de Carrión II & & & & $\mathrm{X}$ & & & & \\
\hline Sauquillo & $\mathrm{X}$ & & & $\mathrm{X}$ & & & & \\
\hline Toro & $\mathrm{X}$ & $\mathrm{X}$ & $\mathrm{X}$ & & & $\mathrm{X}$ & & \\
\hline Trigueros & & $\mathrm{X}$ & & $\mathrm{X}$ & & $\mathrm{X}$ & & \\
\hline Valcavado & & $\mathrm{X}$ & & & & & & \\
\hline Valdefuentes & & & & $\mathrm{X}$ & & & & \\
\hline Villabaruz * & & $\mathrm{X}$ & $\mathrm{X}$ & & & & & \\
\hline Villafloridio (Villorido) & & & $\mathrm{X}$ & $\mathrm{X}$ & & $\mathrm{X}$ & & \\
\hline Villafrechós & $\mathrm{X}$ & $\mathrm{X}$ & & $\mathrm{X}$ & & $\mathrm{X}$ & & \\
\hline Villahélez & & & & $\mathrm{X}$ & & & & \\
\hline Villagonzalo* & $\mathrm{X}$ & $\mathrm{X}$ & & & $\mathrm{X}$ & $\mathrm{X}$ & & \\
\hline Villalpando & & $\mathrm{X}$ & $\mathrm{X}$ & $\mathrm{X}$ & & $\mathrm{X}$ & & \\
\hline
\end{tabular}


JULIO A. PÉREZ CELADA

LA EXPLOTACIÓN DIRECTA DE LA PROPIEDAD DOMINICAL MONÁSTICA EN LA CUENCA DEL DUERO. LOS CLUNIACENSES

\begin{tabular}{|c|c|c|c|c|c|c|c|c|}
\hline LUGARES & $\mathbf{A}$ & B & $\mathrm{C}$ & D & $\mathbf{E}$ & F & G & $\mathbf{H}$ \\
\hline Villalumbroso & $\mathrm{X}$ & $\mathrm{X}$ & & & $\mathrm{X}$ & $\mathrm{X}$ & & \\
\hline Villamez & & & & & & & & $\mathrm{X}$ \\
\hline Villamorco & & $\mathrm{X}$ & & & & & & \\
\hline Villamuera & $\mathrm{X}$ & $\mathrm{X}$ & $\mathrm{X}$ & & & $\mathrm{X}$ & & $\mathrm{X}$ \\
\hline Villanueva del Río & & & & $\mathrm{X}$ & & $\mathrm{X}$ & & \\
\hline Villarmienzo* $^{*}$ & & & & & & & & $\mathrm{X}$ \\
\hline Villarramiel & $\mathrm{X}$ & & & $\mathrm{X}$ & & $\mathrm{X}$ & & \\
\hline Villasarracino & & & & $\mathrm{X}$ & & & & \\
\hline Villasirga & & $\mathrm{X}$ & $\mathrm{X}$ & & & $\mathrm{X}$ & & \\
\hline Villaturde & & $\mathrm{X}$ & & $\mathrm{X}$ & & & & \\
\hline Villibañe & & $\mathrm{X}$ & $\mathrm{X}$ & & & $\mathrm{X}$ & & \\
\hline Villovieco & & & & $\mathrm{X}$ & & & & \\
\hline Villaverde de Volpejera & $\mathrm{X}$ & $\mathrm{X}$ & $\mathrm{X}$ & & & & & $\mathrm{X}$ \\
\hline
\end{tabular}

Leyenda: A: Casas o domos; B: Centros de culto; C: Presencia efectiva de parejas de bueyes; D: Extensión de las heredades expresada en yugos (yugadas); E: Heredades sin estimación de superficie o equipamiento animal; F: Viñas; G: Servidores domésticos; H: Prestaciones personales.

$\left(^{*}\right)$ Lugares cuyos recursos se hallan arrendados, total o parcialmente.

$\left.{ }^{* *}\right)$ Un topónimo aparece repetido cuando su administración se reparte entre la mesa prioral y la de alguno de los oficiales.

$\left.{ }^{(* * *}\right)$ Los topónimos en cursiva corresponden a lugares en los que el monasterio ejerce el dominio exclusivo. 